University of Louisville

ThinkIR: The University of Louisville's Institutional Repository

Electronic Theses and Dissertations

$5-2007$

\title{
The impact of single product and multi-product batches on a printing operation.
}

Dustin Allen Fackler 1980-

University of Louisville

Follow this and additional works at: https://ir.library.louisville.edu/etd

\section{Recommended Citation}

Fackler, Dustin Allen 1980-, "The impact of single product and multi-product batches on a printing operation." (2007). Electronic Theses and Dissertations. Paper 416.

https://doi.org/10.18297/etd/416

This Master's Thesis is brought to you for free and open access by ThinkIR: The University of Louisville's Institutional Repository. It has been accepted for inclusion in Electronic Theses and Dissertations by an authorized administrator of ThinkIR: The University of Louisville's Institutional Repository. This title appears here courtesy of the author, who has retained all other copyrights. For more information, please contact thinkir@louisville.edu. 
THE IMPACT OF SINGLE PRODUCT AND MULTI-PRODUCT BATCHES ON A PRINTING OPERATION

\author{
By \\ Dustin Fackler \\ B.S., University of Louisville, 2006

\begin{abstract}
A Thesis
Submitted to the Faculty of the

University of Louisville

J. B. Speed School of Engineering

as Partial Fulfillment of the Requirements

for the Professional Degree
\end{abstract} \\ MASTER OF ENGINEERING \\ Department of Industrial Engineering
}

May 2007 



\section{THE IMPACT OF SINGLE PRODUCT AND MULTI-PRODUCT BATCHES ON A PRINTING OPERATION}

Submitted by:

Dustin A. Fackler

A Thesis Approved On

(Date)

by the Following Reading and Examination Committee:

Dr. Gail W. Depuy, Thesis Co-Director

Dr. Gerald W. Evans, Thesis Co-Director

Dr. Eric Rouchka 


\section{ACKNOWLEDGEMENTS}

There are several people I would like to thank for their hard work in helping me with my Thesis. First is Dr. Depuy for being my advisor. Your passion for what you do is infectious. It has been a sheer pleasure being your student and Thesis advisee (scientific term there). You always challenge students to learn and to be the best they possibly can, and are always fair and a great person to joke around with outside of class. For that I am forever grateful. Thanks for the Qdoba too! Next I would like to thank Dr. Evans for helping me with the simulation. Since I had not dealt with Arena in two or three years prior to this year I had forgotten it all and had to start at square one. Your assistance in helping me re-learn the software and guiding me through designing the logic is truly appreciated. I would not have gotten very far at all without your expert assistance. I would also like to thank Dr. Eric Rouchka for taking the time out of his busy schedule to sit on my Defense.

Last but certainly not least, I would like to thank my family; mom, dad, Adam, Ryan, and Hilary. It took me a while to get here but darnit I made it! I would never have gotten this far if it had not been for your undying love and support the past eight years. Words simply can not express just how thankful I am to have a family like I have. 


\begin{abstract}
This research will look at a printing operation that prints labels for paint cans. This particular printing operation is a multi-product, single-machine system with stochastic demands that uses a printing press to print the labels on large sheets that may contain one label type (dedicated sheets) or many different label types (mixed sheets). The objective of this thesis is to determine whether to set up the press to print mixed sheets or dedicated sheets in order to minimize the total cost of the current system given three scenarios: one where all label types have approximately the same monthly demand, one where $20 \%$ of the label types have very large demand and the remaining $80 \%$ have small demand, and one where half of the label types have moderately high demand and the other half have moderately low demand. Three simulation models, one for each scenario, are developed to test this objective and to see which scenarios prefer mixed sheets and which prefer dedicated sheets. The decision logic to choose the sheet to print is based on summing the differences of the inventory levels and the reorder points for each label type on the sheet, and choosing the sheet with the minimum value of this equation. The results of the simulations show that, according to this decision logic, all scenarios choose dedicated to print dedicated sheets.
\end{abstract}




\section{TABLE OF CONTENTS}

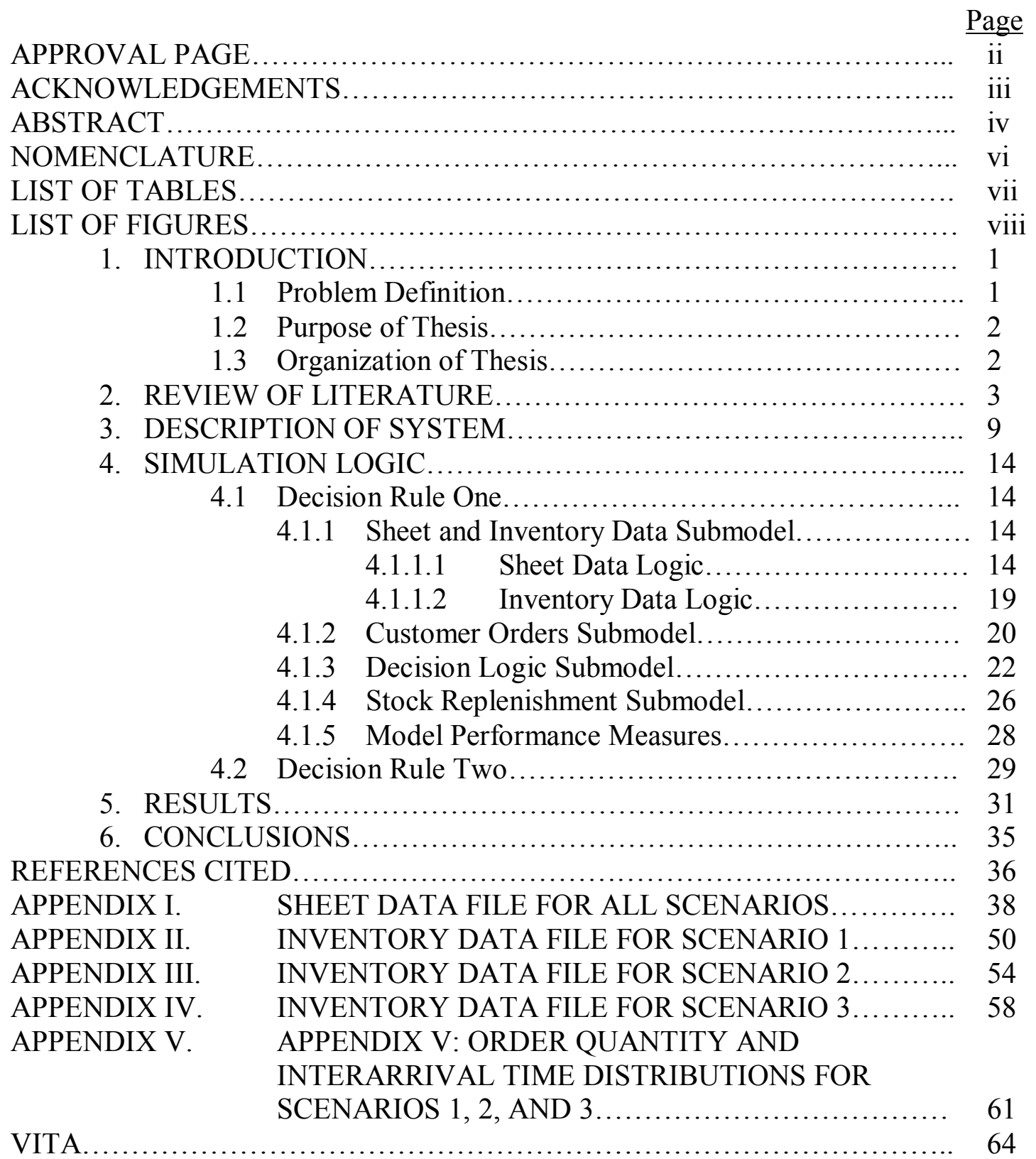




\section{NOMENCLATURE}

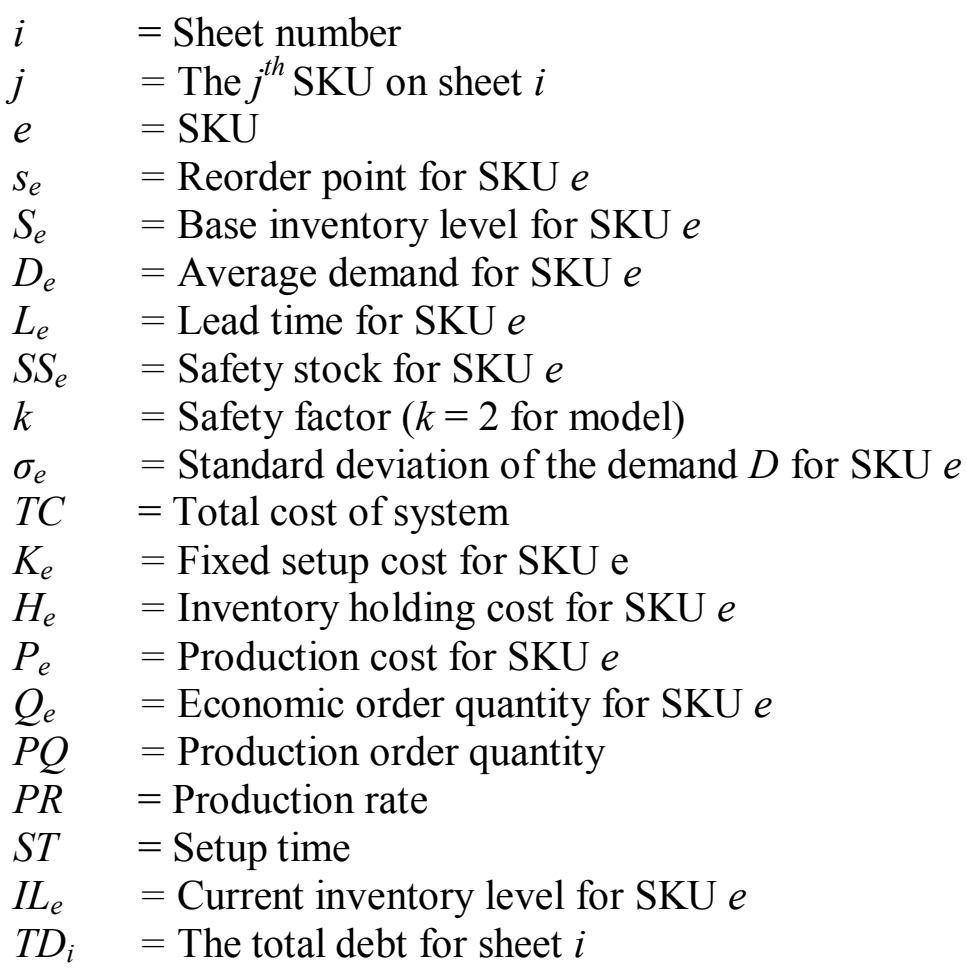




\section{LIST OF TABLES}

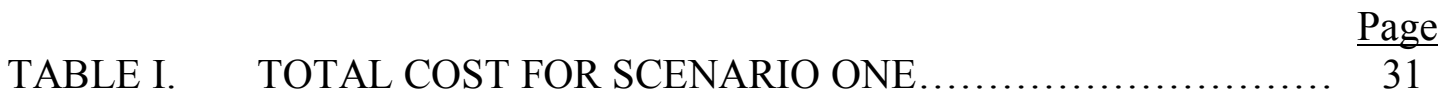

TABLE II. SHEETS CHOSEN IN SCENARIO ONE.................... 32

TABLE III. TOTAL COST FOR SCENARIO $2 \ldots \ldots \ldots \ldots \ldots \ldots \ldots \ldots \ldots \ldots . . \ldots \ldots \ldots$

TABLE IV. SHEETS CHOSEN IN SCENARIO $2 \ldots \ldots \ldots \ldots \ldots \ldots \ldots \ldots \ldots . . . \ldots \ldots$

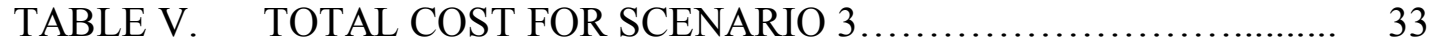

TABLE VI. SHEETS CHOSEN IN SCENARIO 3 ....................... 33 


\section{LIST OF FIGURES}

\begin{tabular}{|c|c|}
\hline 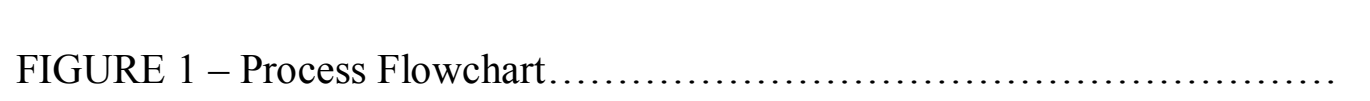 & \\
\hline 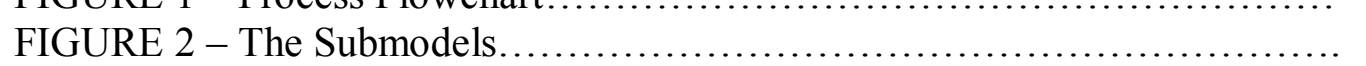 & 14 \\
\hline FIGURE 3 - The Sheet and Inventory Data Submodel.......................... & 15 \\
\hline FIGURE 4 - Preliminary Sheet Data Steps....................................... & 15 \\
\hline FIGURE 5 - Initial Sheet Information................... & 16 \\
\hline FIGURE 6 - Reading Main Sheet Information.. & 17 \\
\hline FIGURE 7 - Reading all Sheets.................. & 18 \\
\hline FIGURE 8 - Preliminary Inventory Data Steps... & 19 \\
\hline 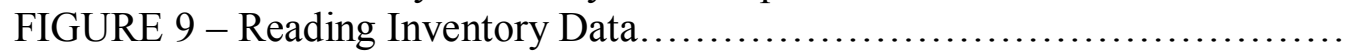 & 19 \\
\hline FIGURE 10 - The Create Module/Assign Module Pair for SKU 25. One Pair is & \\
\hline Used for Each SKU & 20 \\
\hline FIGURE 11 - The Order Processing Portion of the Customer Orders & \\
\hline bmodel................ & 21 \\
\hline FIGURE 12 - The Decision Logic Submodel for Decision Rule Two... & 23 \\
\hline FIGURE 13 - Finding a Sheet Containing the Needed SKU............. & 23 \\
\hline 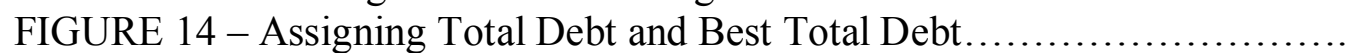 & 24 \\
\hline FIGURE 15 - Calculating Batch Size and Assigning SKUs to Waiting to Print... & 25 \\
\hline & 27 \\
\hline FIGURE 17 - The Decision Logic Submodel for Decision Rule Two .............. & \\
\hline
\end{tabular}




\section{INTRODUCTION}

\subsection{Problem Definition}

This research analyzes a printing operation that is a multi-product, single-machine system with stochastic demands that uses a printing press to print labels for paint cans on large sheets. These sheets may contain one label type or many different label types. There is a large setup cost and small incremental production costs (in this case the cost to print one sheet) associated with running the printing press, both of which contribute to the total cost of the system. The objective is to determine how to set up the production and inventory system to simultaneously meet the demand for the products and minimize this total cost of the system, which includes the fixed cost of setting up the press, the variable cost of printing each sheet, and the cost of holding each label in inventory. Typically in industry machines are restricted to processing only one part type in each batch. However, the printing press can be set up to produce many different part types in a batch. As a result of this unique ability, setting up the press to print many different label types (mixed sheets) or one specific label type (dedicated sheets) could be advantageous to a company depending on the demand for their labels. 


\subsection{Purpose of Research}

Since no closed-form analytic models exist for this problem, the purpose of this research is to develop simulation models using Arena Version 10 (Rockwell Software, 2005) to determine the preferences of mixed sheets and dedicated sheets under three different scenarios, each with their own distinct demand profiles:

- Scenario 1: All label types have approximately the same monthly demand

- Scenario 2: 20\% of the label types have high demand and the remaining $80 \%$ have low demand

- Scenario 3: 25 label types have moderately high demand and 25 label types have moderately low demand

In addition, two decision rules are used to test the sheet selection. The first decision rule is based solely on inventory levels, while the second decision rule is based on setup cost per label produced and number of labels close to a reorder point $s$.

\subsection{Organization of Thesis}

Chapter 2 of the thesis will review previous research on stochastic inventory control, batch production, and simulation. A detailed description of the process follows in Chapter 3, and the three simulation models and the two decision rules are outlined in Chapter 4. Chapter 5 provides the results of the simulations and a discussion of the three models. The research conclusions are summarized in Chapter 6. 


\section{REVIEW OF LITERATURE}

The problem of scheduling multiple products on a single machine with large setup times is well reviewed in the literature. The initial research into this issue, which operated under the assumptions that the demand was constant and the demand and production rates are known, evolved into the Economic Lot Scheduling Problem (ELSP). Elmaghraby (1978) provides a thorough review of the ELSP. More recently, heuristics have been developed for the ELSP case with variable demand. Several examples of these heuristics can be found in the research done by Gascon and Leachman (1988) and Leachman et al. (1988). The constant demand and variable demand cases of the ELSP works for the cases where the demand is deterministic, but there are many situations where the demand is not known.

The case where the demand is unknown and based on probability distributions is known as the Stochastic Lot Scheduling Problem (SLSP). Sox et al. (1999) describe the SLSP as a problem where multiple products, each with a random demand, are scheduled on a single machine with limited production capacity and significant changeovers between products. Vergin and Lee (1978) were the first to address the SLSP. They performed a series of tests that investigated four scheduling models for a problem with 
multiple products, a single machine, and stochastic demand: three based on production lot sizes and cyclic demand (one of which produced enough inventory to account for cyclic fluctuations in demand for all products) and one model they proposed that is designed to produce an item until it met any one of three conditions:

1. The inventory level of item $i$ being produced rises to a proportion of the total inventory level.

2. The inventory level of item $i$ rises to a maximum inventory level $S$ pre-specified for that item.

3. The inventory level of some other item $j$ falls below its reorder point $s$.

When any of these conditions are met, the machine is changed over to produce the item $j$ with the lowest ratio of inventory on hand to usage unless that item is also at its pre-specified maximum level. In this case, a down period is taken. The results of Vergin and Lee's research showed that the two models they analyzed that were based on production lot sizes and cyclic schedules were ineffective with stochastic demand. The model that allowed for cyclic demand fluctuations demonstrated severe flaws, and the model proposed by the authors showed significant improvements over all of the models.

More recent research on the Stochastic Lot Scheduling Problem is reviewed in Zipkin (1986), Gallego (1990), and Sox et al (1999). Zipkin (1986) proposed an approach that combined standard inventory and queueing submodels into classical optimization models in a multi-product, single-machine batch production system with stochastic demand. His models optimize the approximate operating cost of the facility over simple control policies. Gallego (1990) developed a scheduling tool that calculates optimal or near-optimal cyclic inventory review schedules and used this tool to analyze 
its behavior after a disruption perturbs the inventories and to minimize long term average costs of following the review schedule with the recovery policy. The results of his research showed that optimal safety stocks are unique to each product and in the long run the proportion of time an item is in stock is equal to the ratio of backorder to holding cost plus backorder cost. Sox et al (1999) performed a review of the current literature on the Stochastic Lot Scheduling Problem.

Recently, simulation software has been used as a test bed for SLSP's due to its ability to simulate production and inventory control systems together in the context of the physical manufacturing environment. This ability enhances the understanding of the behavior of a particular control system and aids companies in the selection of a particular control system for the manufacturing system under study due to the fast and accurate feedback generated by the simulation model. It is stated though that in order for simulations to be of use, the models must be valid descriptors of the process (Olhager and Persson, 2006). Simulation studies on the Stochastic Lot Scheduling Problem are performed by Kelle and Peak (1996), Olhager and Persson (2006), and Narasimha and Battacharya (2007).

Kelle and Peak (1996) used simulations to compare two production/inventory systems in a chemical production operation: a push system and a pull system. They state that a switch to an adaptive inventory/production control system is appropriate when no further setup reduction costs are possible using a fixed production schedule. A pull system with adaptive production scheduling based on reorder levels and order-up-to levels calculated from the optimal target cycle lengths and safety stocks was proposed. 
In their discussion of production and inventory control systems, Olhager and Persson (2006) specified that systems based on reorder levels and order-up-to levels, also known as reorder point systems, are used in situations with a rate based demand, fixed order quantities, and variable times between orders. One common approach in scheduling production on this type of system is to use a model with a maximum stock level $S$ (order-up-to level) and a minimum stock level $s$ (reorder point), also known as an $(s, S)$ inventory control system or reorder point system. Whenever the inventory level of a certain product drops below the reorder point $s$, a production order is placed for enough of the product to bring the inventory level back up to the maximum level $S$.

Narasimha and Battacharya (2007) studied a two level supply chain containing a retailer and a manufacturer where the manufacturer produces $\mathrm{N}$ products on a single machine for the retailer, and the demand for the retailer is stochastic. The simulation model developed was used to test cyclic service policies (policies where products are produced in a cyclic order, switching from one product to another) on different plant utilization values. Their experiments showed that waiting time estimations for each product are not valid when the machine has a large setup time, but the model is effective in estimating the upper limit on the quantity produced per cycle.

Despite the wealth of research on the stochastic lot scheduling problem, there is a void in the literature regarding scheduling many items for production at the same time on one machine. The research presented in this thesis aims to look into this problem and help fill that gap. 


\section{DESCRIPTION OF SYSTEM}

It should be first noted that the system presented in this thesis, as well as the data used, is not real but is representative of the actual system. The objective is to determine whether to set up the printing press to print only one type of label (SKU) at a time (dedicated sheets) or to print many different SKUs at a time on one sheet (mixed sheets). Once the sheet for production is picked, the press undergoes a 3.5 hour setup and the sheets are printed at a constant rate of five seconds per sheet. After printing, the sheets are separated into individual SKUs and put into inventory. A flowchart of the process can be seen in Figure 1 below.

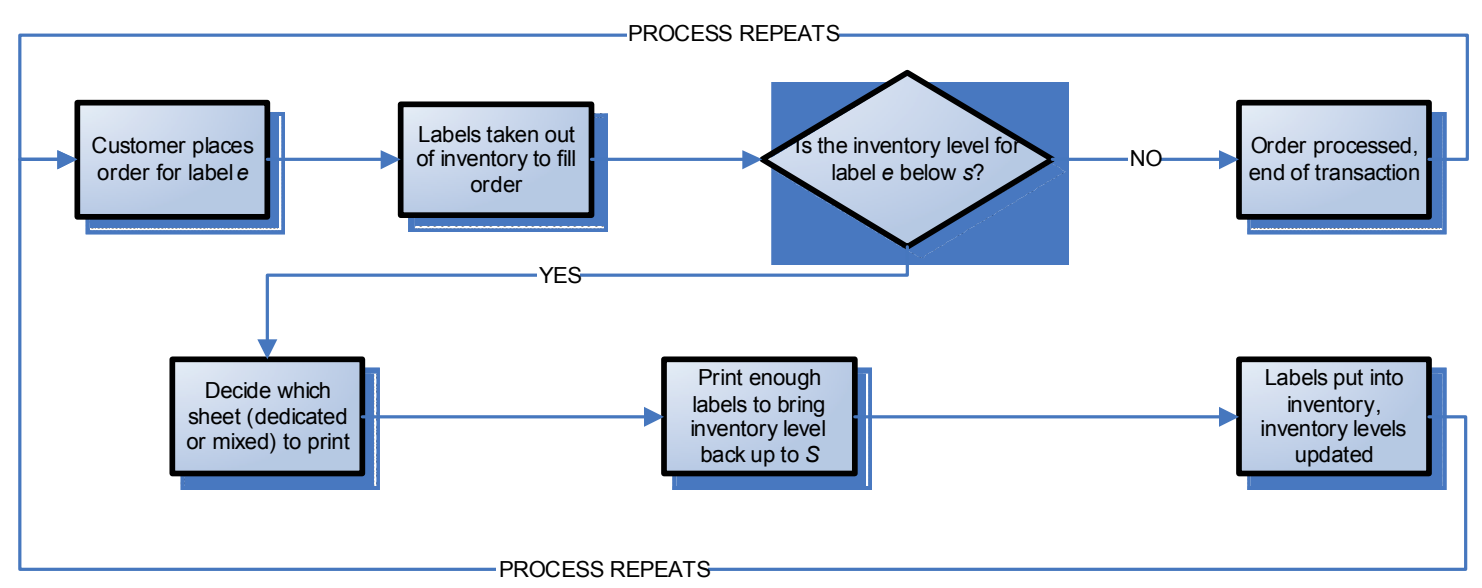

FIGURE 1 - Process Flowchart 
Customer orders arrive randomly for one of 50 different SKUs, with the time between orders (interarrival time) for each SKU being exponentially distributed with means of 1, 1.5, 2, 3, or 6. Each SKU is randomly assigned one of these six interarrival times. It is assumed that customers request only one SKU at a time and that this is a round-the-clock operation. The demand for each SKU is normally distributed and their order quantities under each scenario can be found in the Demand Data section of Appendices II, III, and IV. Orders are taken out of on-hand inventory, but if the on-hand inventory is less than the customer's demand the customer gets whatever is left in inventory and the rest is backordered. The customer will get the remainder of their order when the inventory is sufficiently replenished. All customers whose orders are placed on backorder are assumed to be infinitely patient and never cancel their orders. The system does not keep track of which labels arriving in the future will satisfy which backlogged orders.

The inventory control system in use for this model runs according an $(s, S)$ policy. Whenever the inventory level for a particular SKU drops below its predetermined reorder point $s$, the system sends an order to produce enough of the SKU to bring its inventory level up to its maximum inventory level S. Microsoft Excel 2003 (Microsoft ${ }^{\circledR}$ Corporation, 2003) was used to determine the values for the reorder point $s$ and the maximum inventory level $S$. For each SKU, orders and their quantities were generated for a four year period using the RANDBETWEEN function. The mean and standard deviations for each SKU were calculated using this data and were then plugged into formulas set up to determine each SKU's respective $s$ and $S$ values. 
The reorder point $s$ for a particular SKU $e$ can be calculated many different ways. In this thesis, the following equation was used:

$$
s_{e}=D_{e}\left(L_{e}\right)+S S_{e}
$$

The variable $D$ is the total yearly demand for SKU $e$, and is multiplied by the lead time $L$ for SKU $e$ to get the lead time demand. A function of the standard deviation of the yearly demand $\sigma_{e}$ and a safety factor $k$ (set to two in this thesis), the safety stock $S S$ for SKU $e$ is needed as a buffer to aid in preventing stockouts. The following equation calculates the safety stock:

$$
S S_{e}=k \sigma_{e}
$$

The base stock level $S$ is commonly calculated according to the EOQ model (Olhager and Persson 2006). The EOQ model seeks to find the order quantity that minimizes the total cost of the system, which sums the setup cost $(K)$, inventory holding cost $(H)$, and production cost $(P)$ for all SKUs $e$.

$$
T C=\sum_{e} K_{e}+H_{e}+P_{e}
$$


The value of the economic order quantity $Q$ for each SKU $e$ can be calculated with the following equation, where $D$ is the demand for the item, $K$ is the setup cost, and $H$ is the inventory holding cost:

$$
Q_{e}=\sqrt{\frac{2 K_{e} D_{e}}{H_{e}}}
$$

The two costs used in Equation 4, the fixed setup cost and the inventory holding cost, were set to $\$ 150.00$ and $\$ 0.0221$ respectively. It is assumed that there are no seasonal fluctuations in demand for any SKU and the setup costs and inventory holding costs are the same for each SKU.

The value for the maximum inventory level $S$ is then determined by adding the value for $Q_{j}$ to the reorder point $s$ :

$$
S_{e}=s_{e}+Q_{e}
$$

The lead times for Equation 1 were estimated to be the setup time ( 3.5 hours for all SKUs) and the time to print the EOQ for each SKU $e$ (a production rate $P R$ of five seconds per sheet multiplied by the EOQ for each SKU):

$$
L_{e}=S T+P R \times Q_{e}
$$


Any waiting times, transportation times, and inspection times were assumed to be minimal and consequently were not included. The values for $s$ and $S$ for each SKU can be found in Appendices II, III, and IV.

After an order is sent to print a particular SKU, a decision has to be made as to what specific sheet needs to be printed since each SKU can be found on many different sheets. The system must choose one sheet from among 100 available, all with eight labels per sheet. Fifty of these sheets are dedicated to one specific SKU (one dedicated sheet per SKU) and the other 50 mixed sheets (assigned in a completely random fashion) which have anywhere from two to eight different SKUs per sheet. A list of each sheet and the SKUs assigned to it can be found in Appendix I.

Two decision rules are used to determine which sheet is to be printed. Decision rule one is based on the following logic. For every sheet $i$ containing a particular SKU that is slated for printing, the respective total debts $T D$ for those sheets are calculated by summing the difference between the current inventory level $I L$ and the reorder point $s$ for each SKU $e$ on the sheet (with sheet $i$ containing SKUs $e$ ). The sheet containing the SKU in need that has the best (lowest) total debt value is then selected for production since this sheet has the SKUs that are the closest to their respective reorder points. Equation 7 illustrates the equation used to calculate the total debt for each sheet $i$ :

$$
\text { Total Debt } t_{i}=\sum_{e} I L_{e}-s_{e} \quad \forall i \mid S K U \underline{C} i
$$

After the sheet with the best total debt value is chosen, the production order quantity $P Q$ is determined using Equation 8 and the $S$ and $I L$ values for the SKU $e$ 
originally in need. Equation 8 is used so that any backorders that may occur are accounted for and the production quantity is adjusted accordingly.

$$
P Q=S_{e}-I L_{e}
$$

Decision rule two runs off of the following logic. For each sheet that contains the needed SKU, the following equation is calculated:

$$
Z=\alpha_{1} F-\alpha_{2} G
$$

$F$ is the setup cost per SKU type on the sheet and is calculated as follows:

$$
F=\frac{\text { Sheet Setup Cost }}{\text { Number of SKUs per Sheet }}
$$

$G$ is the number of SKU types on the sheet that is within $\mathrm{X} \%$ of its $s$ value and will be within Y\% of its $S$ value after printing, and $\alpha_{1} \alpha_{2}$ are constants whose values are between zero and one. Arena's (Rockewll Software, 2005) model optimizer OptQuest (OptTek Systems, 2005) is used to find the optimal values for X, Y, $\alpha_{1}$, and $\alpha_{2}$. The sheet that has the lowest $Z$ value is chosen for printing.

The order then moves to a first come first serve queue for its turn to print. As stated above, the printer undergoes a 3.5 hour setup time in preparation for production and prints at a rate of five seconds per sheet. It costs the system $\$ 0.03$ to print one sheet. 
After the sheet is printed it is separated into individual labels and sent immediately to inventory to await a customer order. 


\section{SIMULATION LOGIC}

Arena Version 10 (Rockwell Software, 2005) is used to develop the simulation model of this system with the same logic and same run time (a period of one year, 364 days) for all three scenarios to let inventories cycle through several times. Only the order quantity and interarrival time distributions are changed between scenarios. In order to better organize it, the model is divided into four submodels: Sheet and Inventory Data, Customer Orders, Decision Logic, and Stock Replenishment. The logic contained within each submodel will be outlined in detail. The only changes between decision rule one and decision rule two are to the Decision Logic Submodel.

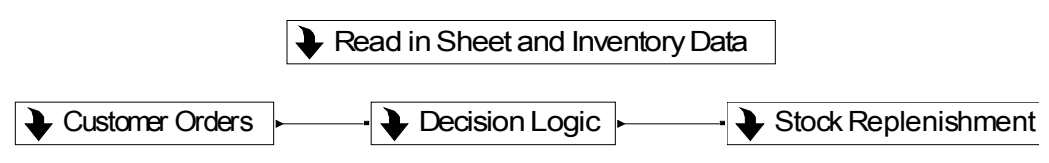

FIGURE 2 - The Submodels

\subsection{Decision Rule One}

\subsubsection{Sheet and Inventory Data Submodel}

All data regarding the sheets, initial inventories, $s$ and $S$ values, and the costs associated with operating the system are read into Arena at the start of the simulation via Excel spreadsheets(Microsoft ${ }^{\circledR}$ Corporation, 2003). The Sheet Data file found in 
Appendix I shows each sheet $i$, the SKUs on each sheet, and number of units of each SKU on sheet $i$ as read into Arena. All setup costs and printing costs are read in from this spreadsheet as well. The Inventory Data files found in the Inventory Data section of Appendices II, III, and IV show the initial inventory level, $s$ and $S$ value, the inventory holding cost (\$/unit/year), and waiting to print inventory as read into Arena. The waiting to print inventory is defined as the quantity of a particular SKU that is waiting to be printed, or the work in process. The Sheet Data and Inventory Data files each have their own respective logic, with the sheet data logic being on the top in Figure 3. Because this logic is only executed during the startup of the simulation, it was not connected to the other submodels.

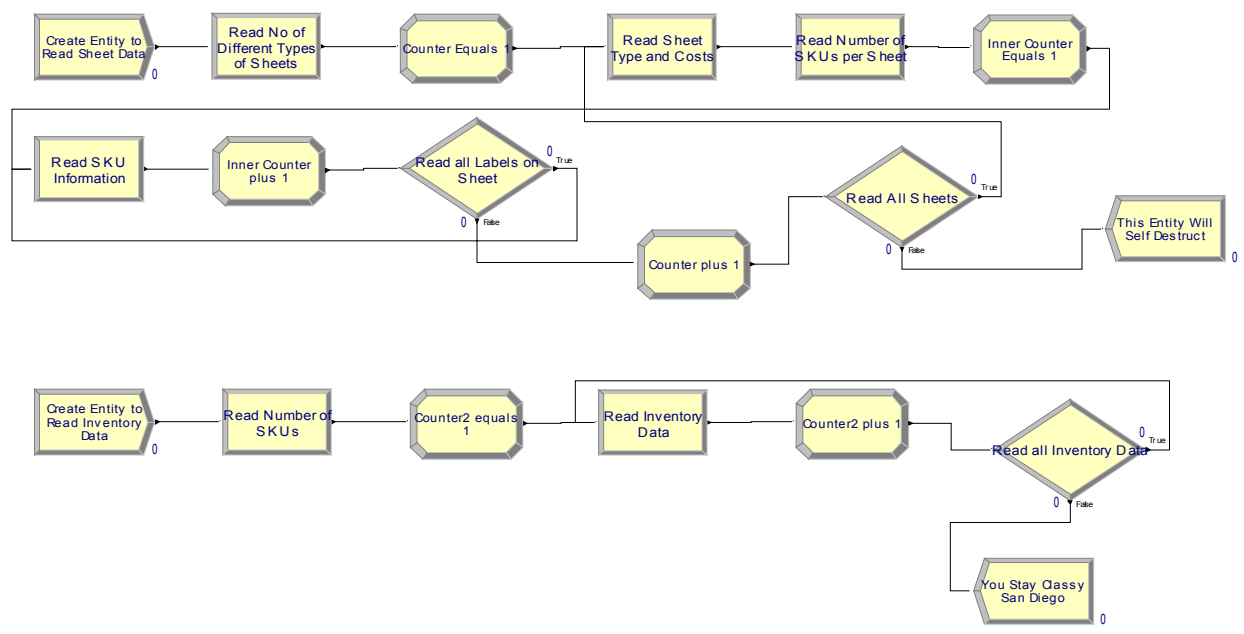

FIGURE 3 - The Sheet and Inventory Data Submodel

\subsubsection{Sheet Data Logic}

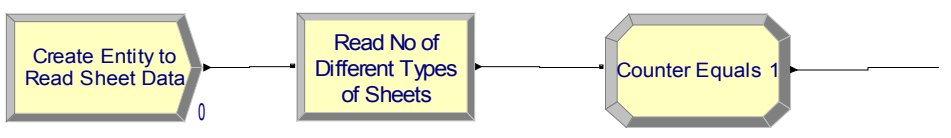


FIGURE 4 - Preliminary Sheet Data Steps

The sheet data logic begins with the modules shown in Figure 4. One entity is created at time zero with the max arrivals set to one so the data is only read once. From here the entity passes through the Read/Write module "Read No of Different Types of Sheets" which reads the variable No of Different Types of Sheets (which saves the number of different types of sheets as 100). Each time the entity passes through a Read/Write module, Arena reads the next successive row in Excel. The variable Counter (which sets an internal counter to one) is then set to one in the following Assign module. In this submodel, Counter is used to represent a particular sheet.

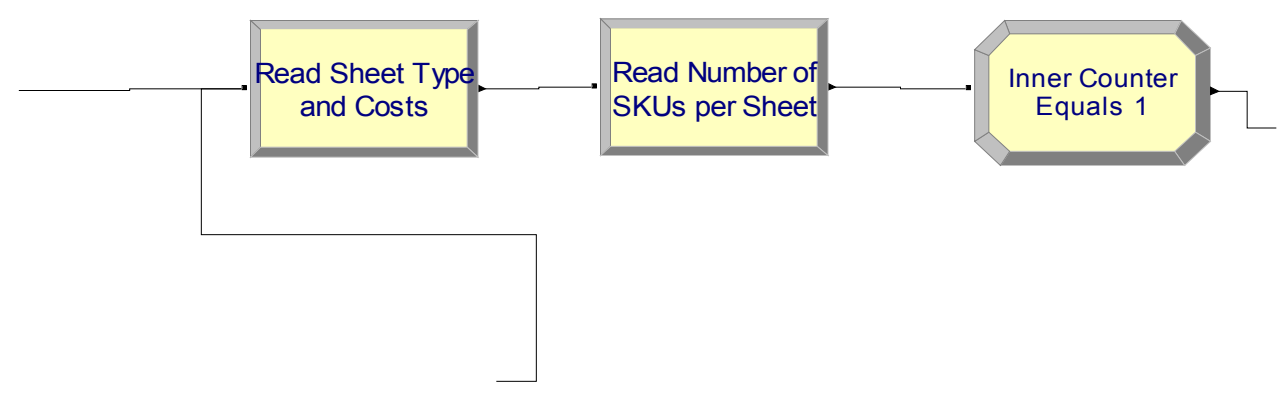

FIGURE 5 - Initial Sheet Information

Next the initial sheet information is read in the modules shown in Figure 4. The entity passes through the Read/Write modules "Read Sheet Type and Costs" and "Read Number of SKUs per Sheet" that define the variable Sheet Type and the one-dimensional array variables Sheet Setup Cost(Counter), Sheet Printing Cost(Counter), and Number of SKUs per Sheet(Counter). One-dimensional array variables use a one dimensional array (i) to reference specific values for the variable. For example, the value of the variable 
Number of SKUs per Sheet(Counter) is used to specify the number of SKUs assigned to sheet $i$. If Counter is set to 95, Arena will reference the $95^{\text {th }}$ row of the Number of SKUs per Sheet array and identify the value for the number of SKUs on sheet 95 (Number of SKUs per Sheet(95) ) as three since there are three SKUs on sheet 95. The variable Inner Counter, which in this submodel is used to represent the $j^{\text {th }} \mathrm{SKU}$ on sheet $i$ is then set to one when the entity reaches the Assign module "Inner Counter equals 1".

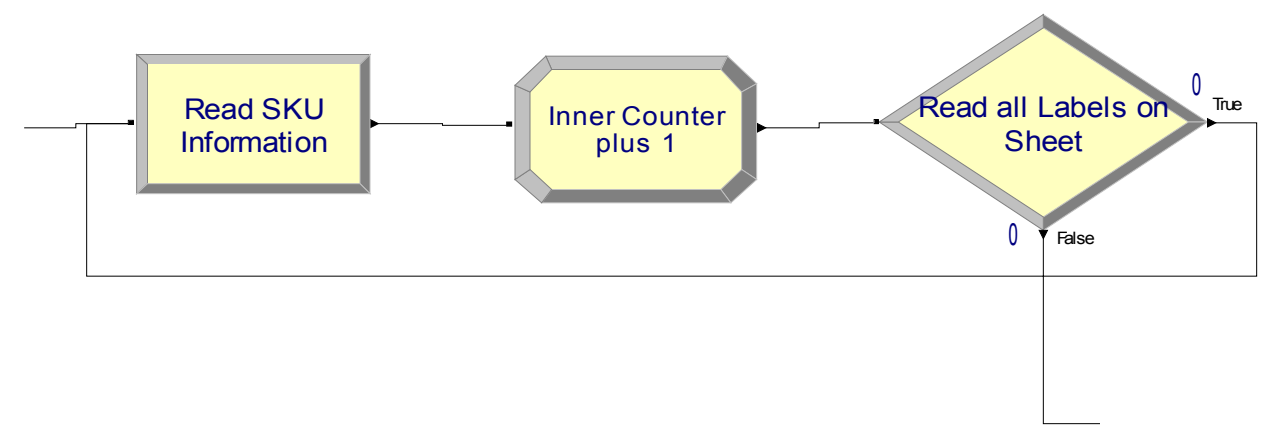

FIGURE 6 - Reading Main Sheet Information

After the initial sheet information is read into the simulation, the entity passes through the "Read SKU Information" module depicted in Figure 6 where the twodimensional array variables $S K U($ Counter, Inner Counter) and No of Units per SKU(Counter, Inner Counter) are read. Similar to one-dimensional array variables, two dimensional array variables use a two-dimensional array $(i, j)$-in this simulation $i$ represents the sheet and $j$ represents the $j^{\text {th }}$ SKU on sheet $i$ - to reference specific values of the variable. For example, when Counter is equal to 54 and Inner Counter is equal to three, Arena will save the value for the third SKU on sheet $54(\operatorname{SKU}(54,3))$ as 10 and the number of units per SKU (No of Units per SKU $(54,3)$ ) as two. After this information is 
read, the entity moves on and one is added to the value of Inner Counter. The Inner Counter is then compared to the value of the variable Number of SKUs per Sheet(Counter) in the Decide module "Read All Labels on Sheet"; if the value of Inner Counter is less than that of Number of SKUs per Sheet(Counter), meaning the simulation hasn't read all of the SKUs on sheet $i$, the entity gets cycled back to read the next values for SKU(Counter, Inne rCounter) and No of Units per SKU(Counter, Inner Counter) on that sheet. This process continues until all SKUs have been read on that sheet.

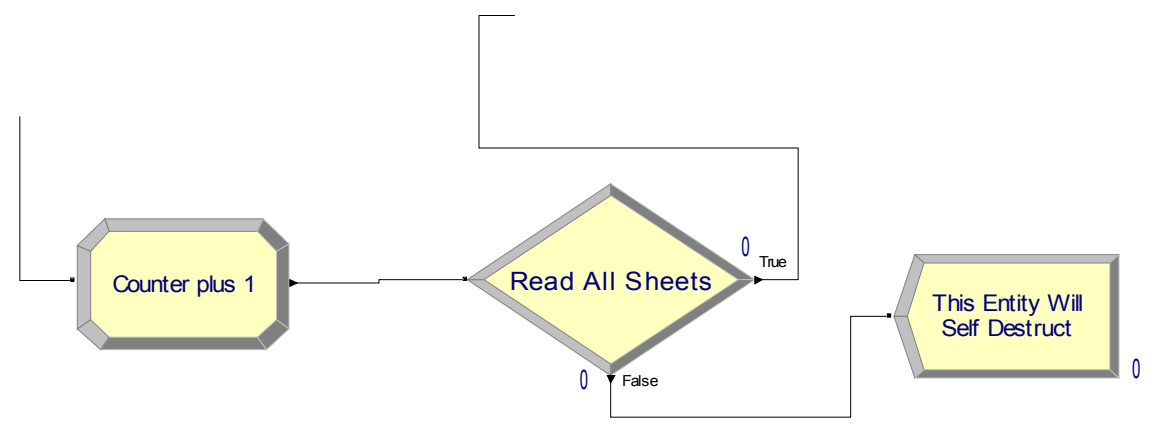

FIGURE 7 - Reading all Sheets

Once all of the SKUs on a particular sheet are read, the entity moves on as seen in Figure 7 and one is added to the value of Counter to represent the next sheet. In the "Read All Sheets" Decision module, if the value for Counter is less than or equal to the variable Number of Different Types of Sheets (which is 100) -meaning not all of the sheets have been read- the entity is cycled back up to the modules in Figure 4 where the process begins again. It should be noted that each time the entity is cycled back and goes through the modules in Figure 4, the value for Inne rCounter is reset to one in order to correctly array the variables. The entity continues to cycle through until all sheets have been read, in which case the entity is disposed. 


\subsubsection{Inventory Data Logic}

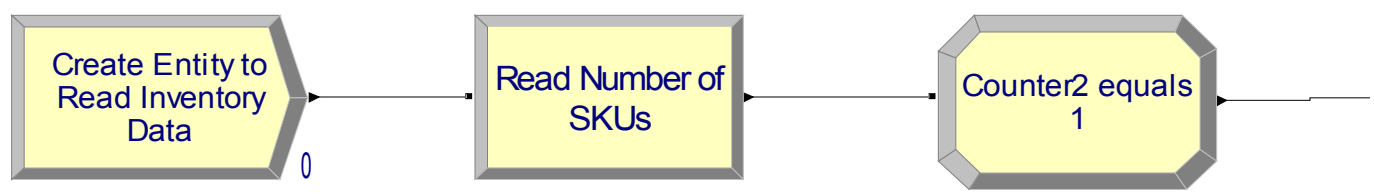

FIGURE 8 - Preliminary Inventory Data Steps

As shown in Figure 7, the inventory data logic begins the same way as the sheet data logic with a Create module that creates one entity at time zero with the max arrivals set to one. The entity is sent to the "Read Number of SKUs" module where the variables Number of SKUs (50 in this case) and Counter2 are then read, with Counter2 in the Inventory Data logic representing a particular SKU.

The inventory data is then read into the model via the modules seen in Figure 9. This section of the logic sets the values for the one-dimensional array variables Inventory Level(Counter2), Big S(Counter2), Little s(Counter2), Unit Holding Cost(Counter2), and Waiting to Print(Counter2) for each SKU via the "Read Inventory Data" module. After this information is read by the entity, it is sent on and one is added to Counter2. The

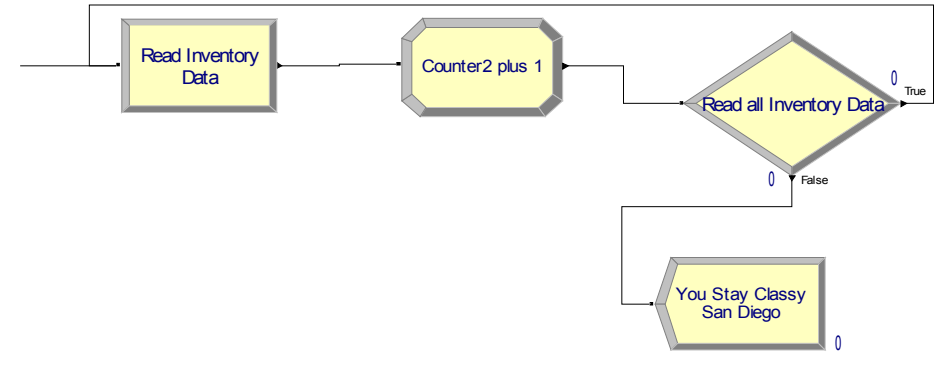

FIGURE 9 - Reading Inventory Data 
resulting value is compared to the variable Number of $S K U$ s in the "Read all Inventory Data" module. If Counter2 is less than 50, the entity is cycled back around to read the data for the rest of the SKUs. If the opposite is true and all sheets have been read, the entity gets disposed. Once the sheet data and inventory data logic are read into the model, the simulation begins with orders entering the system.

\subsubsection{Customer Orders Submodel}

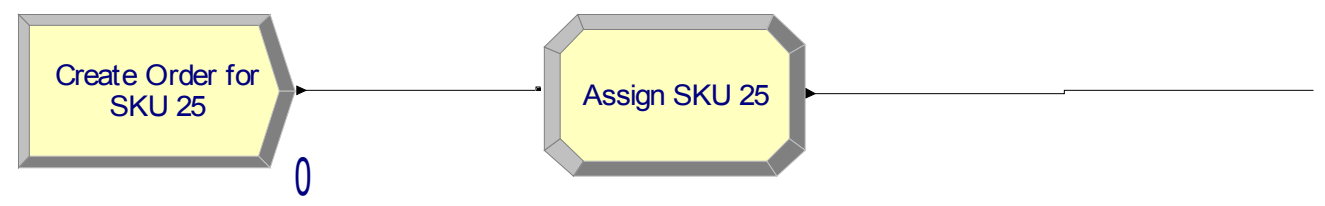

FIGURE 10 - The Create Module/Assign Module Pair for SKU 25. One Pair is Used for Each SKU

The system begins in the Customer Orders Submodel with one Create module and one Assign module per SKU, an example of which can be seen in Figure 10. Entities are created as orders (with one entity per arrival) using exponentially distributed interarrival times. Orders are then assigned two attributes: Ordered SKU (the SKU that was ordered) Demand (the quantity that was ordered), with Demand being generated according to triangular distributions. The attribute Ordered $S K U$ is used to dimension the one and two-dimensional variables in this submodel. Both interarrival time and order quantity distributions are specific to each SKU and their values for each SKU can be found in Appendix V. The triangular distribution was used for the order quantities instead of the 
normal distribution because it is a good approximation of the normal distribution and it eliminates the possibility of the model generating a negative order quantity.

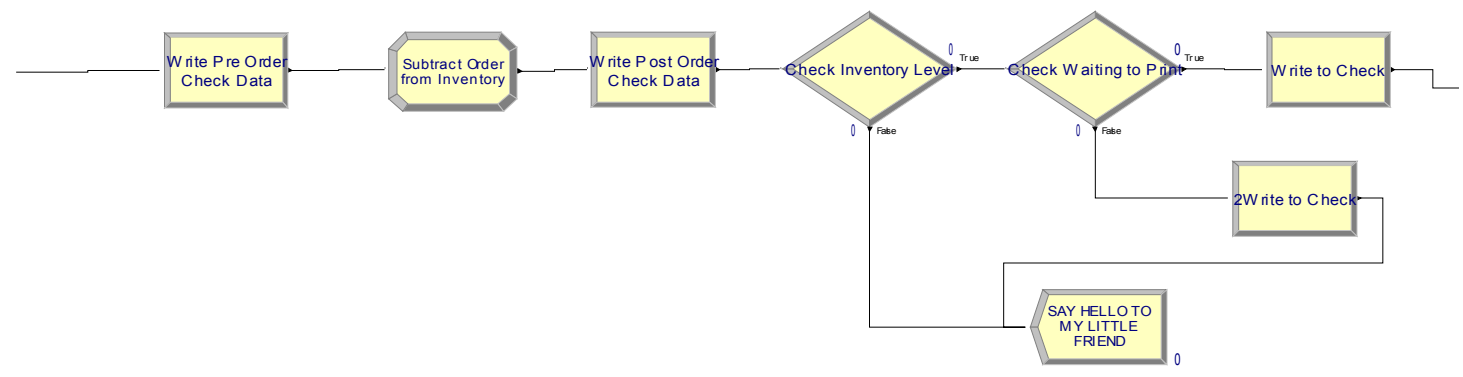

FIGURE 11 - The Order Processing Portion of the Customer Orders Submodel

The following steps are shown in Figure 11. After the order is generated and assigned a SKU and quantity, the entity is sent to the "Subtract Order From Inventory" module where the order quantity is subtracted from the inventory level for the ordered SKU to update its inventory level:

Inventory Level(Ordered SKU) = Inventory Level(Ordered SKU) - Demand

The entity then moves on to the "Check Inventory Level" module where Inventory Level(Ordered SKU) is compared to Little s(Ordered SKU). If Inventory Level(Ordered $S K U)$ is greater than Little s(Ordered SKU), the entity is disposed, but if the opposite is true the entity gets sent to the Decide module "Check Waiting to Print". This decision is used to ensure that another order isn't sent if there is already an order waiting to be printed that will bring the inventory level for the ordered SKU above its $s$ value. If the variable Waiting to Print(Ordered SKU) is less than or equal to the ordered 
SKU's $s$ value minus the minimum of its negative inventory level and 0 , the entity is sent to the decision logic module in preparation for printing.

Waiting to Print(Ordered SKU) $\leq$ Little s(Ordered SKU) - Min[Inventory Level(Ordered SKU), 0]

The minimum of the inventory level and 0 is used to account for any negative inventory so all backorders are filled. If Waiting to Print(Ordered SKU) is greater than this value, the entity is disposed.

\subsubsection{Decision Logic Submodel}

The next step for the entity is the Decision Logic submodel depicted in Figure 12. This submodel determines exactly what sheet to print and how many of it is needed. When an entity first enters the Decision Logic submodel, the attribute Best Total Debt is defined and set to 99999 so that the model can compare the best total debt for each sheet. The value 99999 is used to initialize this variable to ensure that a sheet is chosen. Variables Counter3 and Inner Counter3 are also defined and set to one with Counter3 representing a sheet $i$ and Inner Counter 3 representing the $j^{\text {th }}$ SKU on sheet $i$.

After both counters are set, the entity searches all sheets to find one that contains the ordered SKU (seen in Figure 13). This process begins with the "Search for SKU on Sheets" Decision module that is used to see if the value of SKU(Counter3, Inner Counter3) is equal to the value of the variable Ordered $S K U$ that was assigned in the Customer Orders module. If SKU(Counter3, Inner Counter3) is not equal to Ordered $S K U$, the entity is sent to the Decision Module "2Read All SKUs on Sheet" to make sure 


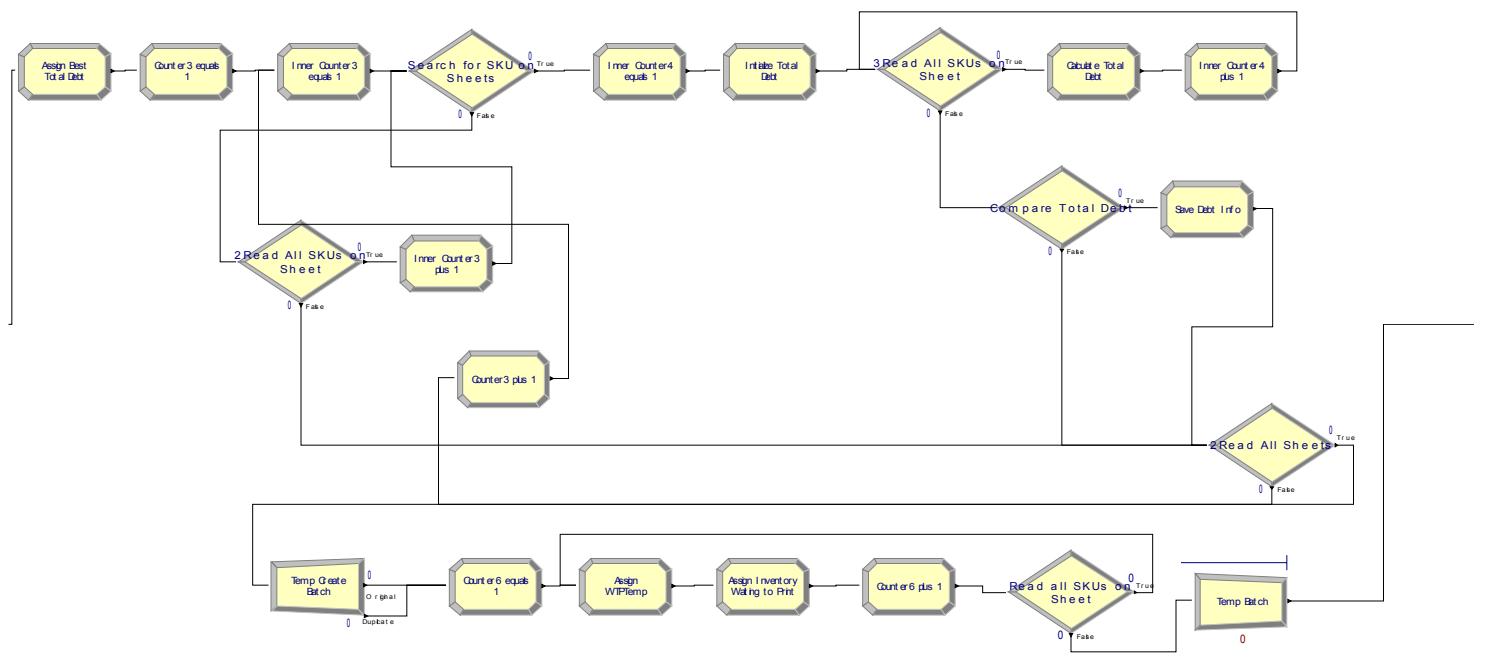

FIGURE 12 - The Decision Logic Submodel for Decision Rule One

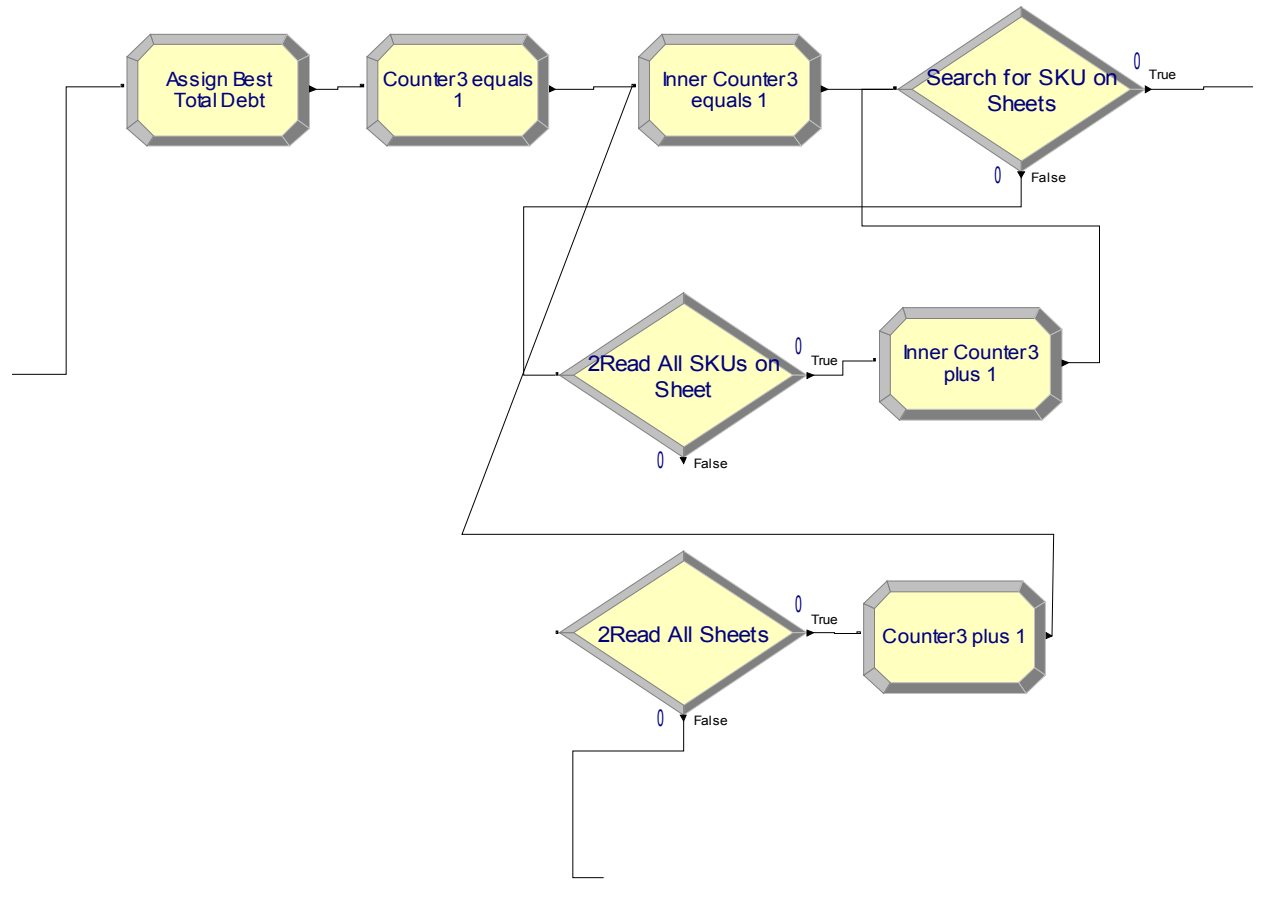

FIGURE 13 - Finding a Sheet Containing the Needed SKU 
that all SKUs on sheet $i$ are checked; if Inner Counter3 is less than the value of Number of SKUs per Sheet(Counter3), the entity boogies along to add one to Inner Counter3 and is then sent back to the "Search for SKU on Sheets" module to check the new value of SKU(Counter3, InnerCounter3). When all SKUs on sheet $i$ are read and Inner Counter3 is equal to Number of SKUs per Sheet(Counter3), the entity moseys on down to the "2Read All Sheets" Decide module to make sure all sheets are read. In this module, if Counter3 is less than the variable No of Different Types of Sheets, one is added to Counter 3 and the entity is cycled back to reset Inner Counter3 at one and the next sheet is read.

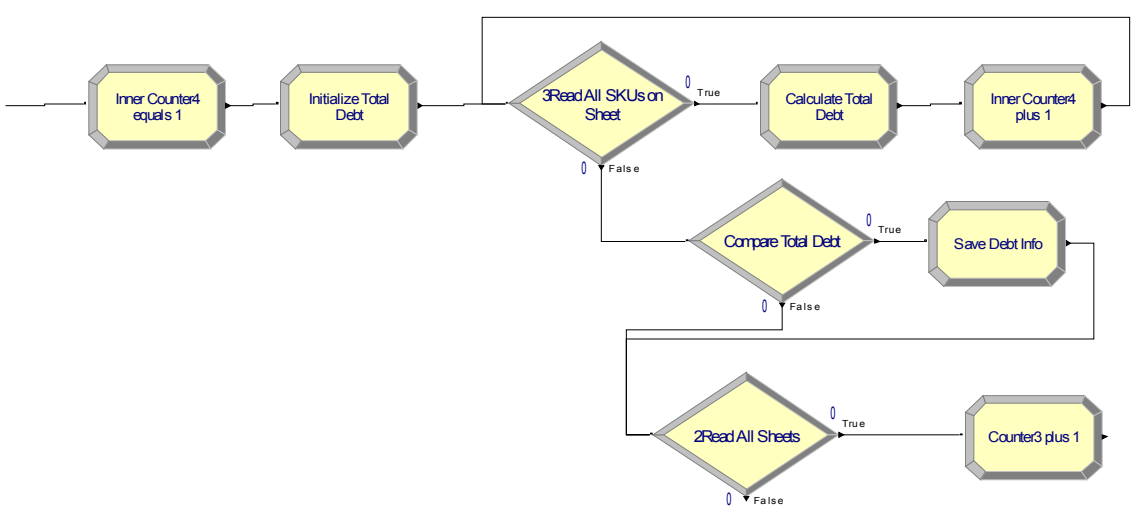

FIGURE 14 - Assigning Total Debt and Best Total Debt

Once a sheet is found in the "Search for SKUs on Sheets" Decide module that contains the ordered SKU [SKU(Counter3, InnerCounter3) = Ordered SKU], the entity moves on to determine the best total debt of the sheet according to the logic seen in Figure 14. A variable InnerCounter4 is first set to one and the attribute Total Debt is initialized at zero. If InnerCounter4 is less than or equal to Number of SKUs per Sheet(Counter3), the entity passes on to calculate Total Debt according to Equation 8. 
The debt for the first SKU on the sheet is calculated and added to the attribute Total Debt and then the value of Inner Counter4 is increased by one.

After InnerCounter4 is increased, the entity cycles back to the "Search for SKUs on Sheets" module where Inner Counter4 is compared to Number of SKUs per Sheet(Counter3) again. The entity continues cycling until all SKUs on the sheet have been read and the total debt for the entire sheet has been calculated. After all of the SKUs on the sheet have been read, the entity is sent down to the "Compare Total Debt" module where Total Debt for the sheet is compared to the attribute Best Total Debt. If Total Debt for this sheet is lower than the value for Best Total Debt, Best Total Debt is reset to the value of Total Debt for this sheet. In addition, the sheet number for this sheet is saved as an attribute Best Sheet and the value of Counter 3 is saved as the attribute CounterTemp. If Total Debt is bigger than Best Total Debt, nothing happens. In either case, the entity moves on to the "2Read All Sheets" module to see if all sheets have been read. If Counter 3 is less than No of Different Types of Sheets, one is added to Counter3 and the entity gets cycled back to the beginning of the logic to reset InnerCounter 3 to one.

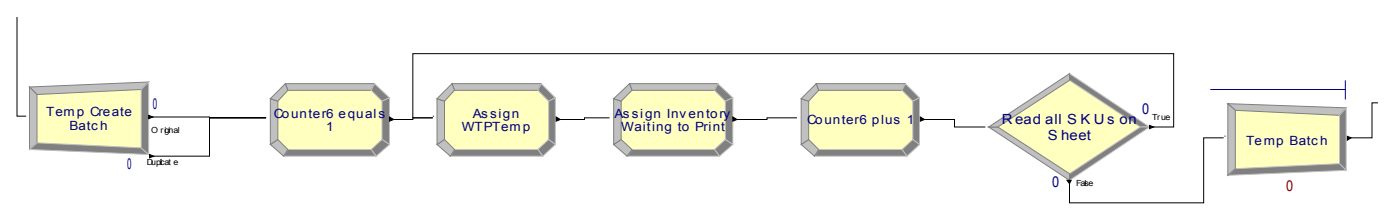

FIGURE 15 - Calculating Batch Size and Assigning SKUs to Waiting to Print 
Once all sheets have been read, the entity gets sent to the logic represented in Figure 15. The production quantity $P Q$ is determined first using a modified version of equation 6 where $e$ is the ordered SKU.

$$
P Q=\frac{S_{e}-I L_{e}}{\text { No of Units per SKU (Best Sheet, Counter Temp })}
$$

The entity gets duplicated into a batch based on $P Q$ and each new entity is added to the waiting to print inventory. Counter6 is set equal to one and the attribute WTPTemp is saved as the value of $S K U$ (Best Sheet, Counter6). The waiting to print inventory is now added using the following equation:

Waiting to Print $($ WTPTemp $)=$ Waiting to Print $($ WTPTemp $)+$ No of Units per SKU(Best Sheet, Counter6)

From here, all SKUs on the sheet are added and the newly created entities are temporarily batched into one entity and sent to the Stock Replenishment submodel.

\subsubsection{Stock Replenishment Submodel}

Once an entity enters the Stock Replenishment submodel, it goes to a first come first serve queue where orders wait until the printing press is idle before proceeding to another queue where the setup costs are calculated and the order waits 3.5 hours for the 


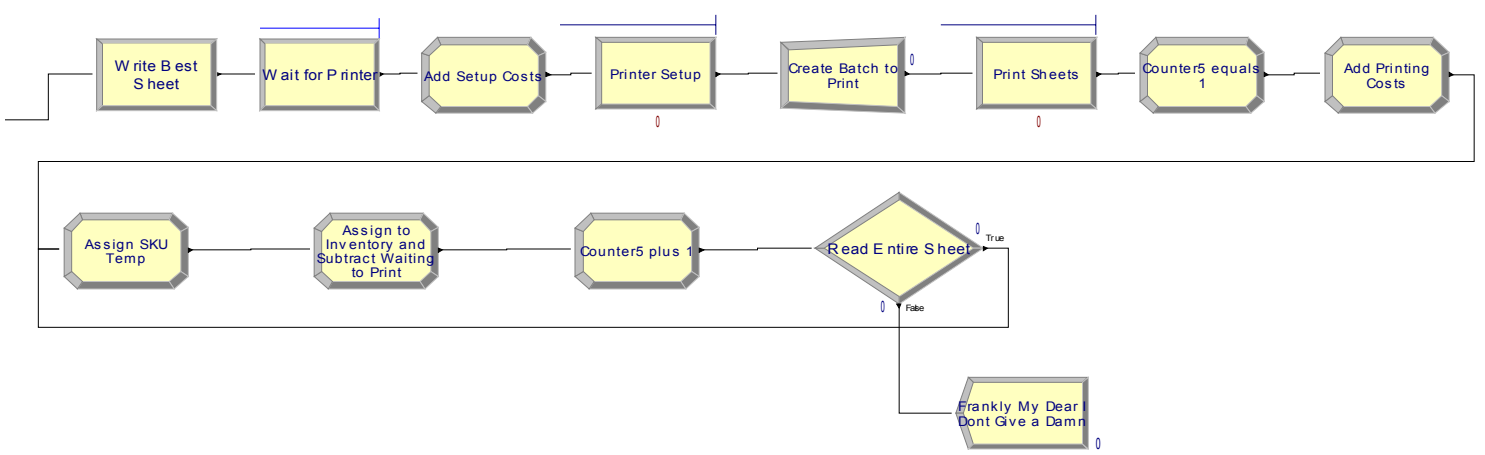

FIGURE 16 - The Stock Replenishment Submodel

printer to be set up. A running tab of the setup cost is kept via the Assign module "Add Setup Cost".

Total Setup Cost $=$ Total Setup Cost + Sheet Setup Cost(Best Sheet)

Before printing, the order gets separated into individual sheets and printed at a constant rate of five seconds per sheet. After printing, a variable Counter 5 is assigned and a running tab of the printing cost is calculated according to the following equation:

Total Printing Cost $=$ Total Printing Cost + Sheet Printing Cost(Best Sheet)

Next, each sheet is separated into individual SKUs which are subsequently added to inventory and taken out of waiting to print inventory. To do this, an attribute SKUTemp(Best Sheet, Counter5) is assigned to each entity in the "Assign SKU Temp" module and added to inventory in the "Assign to Inventory and Subtract From Waiting to Print" module using the following equation: 
Inventory Level(SKUTemp) = Inventory Level(SKUTemp) + No of Units per SKU(Best Sheet, Counter5)

The SKUs are taken out of the waiting to print inventory using Equation 16:

Waiting to Print $($ WTPTemp $)=$ Waiting to Print $($ WTPTemp $)-$ No of Units per SKU(Best Sheet, Counter6)

The variable Total Ordering Cost is also calculated:

Total Ordering Cost $=$ Total Ordering Cost $+\frac{\text { Sheet Setup Cost }(\text { Best Sheet })+\text { Sheet } \operatorname{Pr} \text { int ing Cost }(\text { Best Sheet })}{\text { Number of SKUs per Sheet }(\text { Best Sheet })}$

After these calculations, one is added to Counter 5 and the entire sheet is read and then disposed once all SKUs have been added to inventory.

\subsubsection{Model Performance Measures}

In order to gain perspective on the performance of the system, several measures are specified in the Statistics module: Total Printing Cost, Total Setup Cost, Inventory Holding Cost, and Total Cost. Total Cost is calculated at the end of the simulation in order to add the final values of the variables Sheet Printing Cost and Sheet Setup Cost. The statistics Total Printing Cost and Total Setup Cost are also calculated upon conclusion of the simulation in order to report the final values of Sheet Printing Cost and Sheet Setup Cost in the model output. The statistic Inventory Holding Cost is calculated as a time-average sample mean of the total inventory holding cost over all SKUs. A tally 
statistic entitled Best Sheet Count was also used to count the number of dedicated sheets and mixed sheets chosen to be printed.

\subsection{Decision Rule Two}

The only submodel that changes for decision rule two is the Decision Logic submodel. The model window can be seen below in Figure 17.

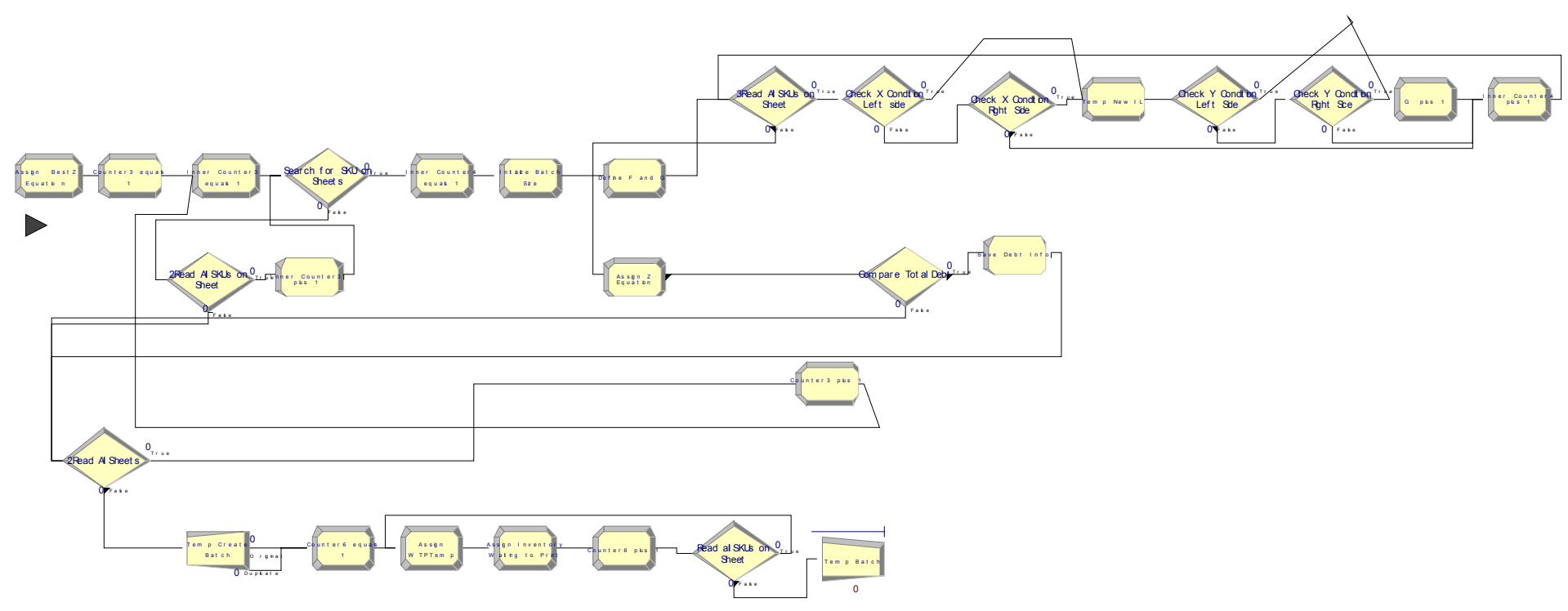

FIGURE 17 - Decision Logic Submodel for Decision Rule Two

The only changes to the logic are the following. First, instead of Best Total Debt, the sheet selection attribute is Best $Z$ Equation. After a sheet is found that contains the needed SKU, two attributes are assigned: Temp Batch Size, assigned according to Equation 11, and Sheet Temp which is assigned as the current value of Counter3. The values for $F$ and $G$ are then assigned, with $F$ being calculated according to Equation 10 and $G$ being initialized at zero. $G$ is then calculated by a series of decision modules. 
Read all SKUs on Sheet makes sure that all SKUs on the sheet are accounted for. The current inventory level is then compared to the optimal value of $\mathrm{X}$ as decided by OptQuest (OptTek, 2005). If the inventory level for a SKU is not within X\% of its $s$ value, it is sent to add one to Inner Counter4, which was assigned after the logic found a sheet containing the needed SKU, and the next SKU is checked. If a SKU is within $\mathrm{X} \%$ of its $s$ value, the attribute Temp New $I L$ is assigned to the entity according to Equation 13 which calculates the future inventory level of this SKU if this particular sheet is printed.

Next, Temp New IL is checked to see if this new value is within Y\% of the SKU's $S$ value after printing. If it is not, one is added to Inner Counter 4 and the next SKU is checked. If it is, one is added to $G$, then one is added to Inner Counter4, and the next SKU is checked. Once all SKUs are checked, the value for $Z$ is calculated according to Equation 9, and this value is compared to what is saved as Best $Z$ Equation. If this $Z$ value is lower, it is saved as the new Best Z Equation and the sheet is saved as Best Sheet and sent on to find another sheet. If it isn't, the entity simply moves on and the current Best $Z$ Equation and Best Sheet remain. The rest of the model for decision rule two is unchanged from that of decision rule one. 


\section{RESULTS}

Three scenarios were modeled to see the preference for mixed sheets and dedicated sheets for different demand profiles. The same logic was used in all three scenarios, only the order quantities and interarrival times changed. Scenario 1 has approximately equal monthly demand for all 50 sheets, scenario 2 has $20 \%$ (10 SKUs) with high monthly demand and $80 \%$ (40 SKUs) with low monthly demand, and scenario 3 has 25 SKUs with moderately high monthly demand and 25 SKUs with moderately low monthly demand. Each scenario was run for a period of 364 days to allow the inventory for each SKU to cycle through their respective $s$ and $S$ values several times. In addition, a warm-up period of 90 days was used to let the model reach steady state before gathering statistics. For scenario one, the cost and sheet statistics from the simulation output are shown below in Tables I and II.

\section{TABLE I}

\section{TOTAL COST FOR SCENARIO ONE}

DECISION RULE \#1

\begin{tabular}{|l|r|}
\hline \multicolumn{1}{|c|}{ Statistic } & \multicolumn{2}{c|}{ Cost } \\
\hline Inventory Holding Cost & $\$ 30,562.28$ \\
\hline Total Printing Cost & $\$ 20,152.17$ \\
\hline Total Setup Cost & $\$ 19,200.00$ \\
\hline
\end{tabular}

DECISION RULE \#2

\begin{tabular}{|l|r|}
\hline \multicolumn{1}{|c|}{ Statistic } & \multicolumn{1}{c|}{ Cost } \\
\hline Inventory Holding Cost & $\$ 89,611.68$ \\
\hline Total Printing Cost & $\$ 37,504.41$ \\
\hline Total Setup Cost & $\$ 6,150.00$ \\
\hline \multicolumn{2}{|c|}{ Total Cost } \\
\hline
\end{tabular}


TABLE II

\section{SHEETS CHOSEN IN SCENARIO ONE}

DECISION RULE \#1

\begin{tabular}{|l|r|}
\hline Sheets & Quantity Chosen \\
\hline Dedicated sheets 1-50 & 986 \\
\hline Mixed Sheets 51-100 & 0 \\
\hline
\end{tabular}

DECISION RULE \#2

\begin{tabular}{|l|r|}
\hline Sheets & Quantity Chosen \\
\hline Dedicated sheets 1-50 & 0 \\
\hline Mixed Sheets 51-100 & 1,127 \\
\hline
\end{tabular}

The cost and sheet statistics for scenario 2 can be seen below in Tables III and IV.

TABLE III

TOTAL COST FOR SCENARIO 2

DECISION RULE \#1

\begin{tabular}{|l|r|}
\hline \multicolumn{1}{|c|}{ Statistic } & Cost \\
\hline Inventory Holding Cost & $\$ 24,484.12$ \\
\hline Total Printing Cost & $\$ 17,893.38$ \\
\hline Total Setup Cost & $\$ 15,150.00$ \\
\hline
\end{tabular}

Total Cost
DECISION RULE \#2

\begin{tabular}{|l|r|}
\hline \multicolumn{1}{|c|}{ Statistic } & \multicolumn{1}{|c|}{ Cost } \\
\hline Inventory Holding Cost & $\$ 151,672.60$ \\
\hline Total Printing Cost & $\$ 53,754.27$ \\
\hline Total Setup Cost & $\$ 6,450.00$ \\
\hline
\end{tabular}

Total Cost

TABLE IV

SHEETS CHOSEN IN SCENARIO 2

DECISION RULE \#1

\begin{tabular}{|l|r|}
\hline Sheets & Quantity Chosen \\
\hline Dedicated sheets 1-50 & 805 \\
\hline Mixed Sheets 51-100 & 0 \\
\hline
\end{tabular}

DECISION RULE \#2

\begin{tabular}{|l|r|}
\hline Sheets & Quantity Chosen \\
\hline Dedicated sheets 1-50 & 0 \\
\hline Mixed Sheets 51-100 & 1,699 \\
\hline
\end{tabular}

Cost and sheet statistics for scenario 3 can be seen below in Tables V and VI. 
TABLE V

TOTAL COST FOR SCENARIO 3

DECISION RULE \#1

\begin{tabular}{|l|r|}
\hline \multicolumn{1}{|c|}{ Statistic } & \multicolumn{2}{|c|}{ Cost } \\
\hline Inventory Holding Cost & $\$ 31,944.82$ \\
\hline Total Printing Cost & $\$ 25,149.30$ \\
\hline Total Setup Cost & $\$ 20,550.00$ \\
\hline
\end{tabular}

Total Cost

$\$ 77,644.12$
DECISION RULE \#2

\begin{tabular}{|l|r|}
\hline \multicolumn{1}{|c|}{ Statistic } & \multicolumn{1}{|c|}{ Cost } \\
\hline Inventory Holding Cost & $\$ 137,637.78$ \\
\hline Total Printing Cost & $\$ 55,228.80$ \\
\hline Total Setup Cost & $\$ 9,450.00$ \\
\hline
\end{tabular}

Total Cost

TABLE VI

\section{SHEETS CHOSEN IN SCENARIO 3}

DECISION RULE \#1

\begin{tabular}{|l|r|}
\hline Sheets & Quantity Chosen \\
\hline Dedicated sheets 1-50 & 1,127 \\
\hline Mixed Sheets 51-100 & 0 \\
\hline
\end{tabular}

DECISION RULE \#2

\begin{tabular}{|l|r|}
\hline Sheets & Quantity Chosen \\
\hline Dedicated sheets 1-50 & 0 \\
\hline Mixed Sheets 51-100 & 1,872 \\
\hline
\end{tabular}

For decision rule number one, none of the three scenarios chose a mixed sheet. When you take the Total Debt decision criteria into account though, this makes sense. Once an SKU $e$ drops below its $s$ value, the chances are slim that there will be other SKUs who share a mixed sheet with SKU $e$ that will be closer to their $s$ values than SKU $e$. There is too much variation among inventories of each SKU to expect this to happen. In addition to this, for dedicated sheets Total Debt is only calculated for one SKU while with mixed sheets it is calculated for the total debt of the ordered SKU plus up to seven more SKUs. The end result is low Total Debt values for dedicated sheets and very high Total Debt values for mixed sheets, thus ensuring that mixed sheets never get chosen. 
Decision rule number two yielded the opposite results; none of the three scenarios chose a dedicated sheet. When looking at the equation, the $F$ value is just too big for dedicated sheets to overcome compared to mixed sheets since this value is the setup cost divided by the number of SKUs on the sheet. The result is that the large $F$ values on dedicated sheets ensure that they are not chosen.

Decision rule number one resulted in much lower inventory, printing, and total costs than decision rule number two. The only cost where decision rule number two is lower than number one is setup cost. The reason for this difference is that the mixed sheets were chosen in a completely random fashion with no rhyme or reason, so SKUs other than the needed SKU probably do not need any more inventory. As a result, decision rule number two produced a lot of SKUs that weren't needed. This drove up printing costs since so much more was produced, and drove up inventory costs since there were so many more labels to store. Since a larger variety of labels is produced at a time, though, this resulted in fewer setups, which explains the lower setup costs. 


\section{CONCLUSIONS}

Simulations were developed in Arena to represent three different scenarios, each with its own demand pattern: one where all label types have approximately the same monthly demand, one where 10 labels have high demand and 40 have low demand, and one in-between with 25 labels having moderately high demand and 25 labels have moderately low monthly demand. Results from all three simulations suggest that if a decision on what sheet to print is chosen based on a SKU's inventory level relative to its $s$ value, dedicated sheets are the preferred choice.

Since this model assumed that customers are infinitely patient and never cancel their orders, it is suggested that future research concentrates on expanding the model to include deadlines and reneging. In addition, different decision parameters for choosing a sheet should be explored in order to see if systems show the same preference for dedicated sheets as displayed in this thesis. An advanced way to design mixed sheets based on SKUs with low inventory levels at the time of printing, as opposed to sheets that are randomly assigned and fixed so they cannot change (as was done in this thesis), needs to be explored too as this "smarter" logic could help to lower costs. 


\section{LIST OF REFERENCES}

Arena Version 10. 2005. Rockwell Software. Milwaukee, Wisconson.

Benjaafar, S., Sheikzadeh, M. 1996. Relationships between batch sizes, scheduling policies, and lead times in manufacturing systems. Proceedings of the 1996 IEEE International Conference on Robotics and Automation pp. 2787-2792.

Elmaghraby, S.E. 1978. The economic lot scheduling problem (ELSP): review and extensions. Management Science 24:587-598.

Gascon, A., Leachman, R.C. 1988. A dynamic programming solution to the dynamic, multi-item single-machine scheduling problem. Operations Research 36:50-56.

Gascon, A., Leachman, R.C., Lefrancois, P. 1994. Multi-item, single-machine scheduling problem with stochastic demands: a comparison of heuristics. International Journal of Production Research 32(3):583-596.

Kelle, P., Peak, D. 1996. A comparison of fixed and adaptive type controls for multiproduct processing. International Journal of Production Economics 45:139-146.

Kelton, W.D., Sadowski, R.P., Sturrock, D.T. 2007. Simulation With Arena, Fourth Edition New York, NY:McGraw-Hill.

Leachman, R.C., Gascon, A. 1988. A heuristic scheduling policy for multi-item singlemachine production systems with time-varying stochastic demands. Management Science 34(3): 377-390.

Microsoft Excel 2003. Microsoft Corporation. Redmond, Washington.

Narasimha, K.B., Bhattacharya, S. 2007. Lead time minimization of a multi-product, single-processor system. International Journal of Production Economics 106: 28:40.

Olhager, J., Perrson, F. 2006. Simulating production and inventory systems: a learning approach to operational excellence. Production Planning and Control 17(2):113-127. 
OptQuest. 2005. OptTek Systems, Inc. Boulder, Colorado.

Sox, C.R., Jackson, P.L, Bowman, A., and Muckstadt, J.A. 1999. A review of the stochastic lot scheduling problem. International Journal of Production Economics 62: 181-200.

Vergin, R.C., Lee, T.N. 1978. Scheduling rules for the multiple product single machine system with stochastic demand. INFOR 16:64-73.

Zipkin, P. H. 1986. Models for design and control of stochastic, multi-item batch production systems. Operations Research 34(1): 91-104. 
APPENDIX I: SHEET DATA FILE FOR ALL SCENARIOS 
SHEET DATA

\begin{tabular}{|c|c|c|c|}
\hline & $\begin{array}{l}\text { Sheet } \\
\text { Information }\end{array}$ & $\begin{array}{l}\text { \# of Units } \\
\text { per } \\
\text { SKU(I, J); } \\
\text { Sheet } \\
\text { Setup } \\
\text { Cost(I) } \\
\end{array}$ & $\begin{array}{l}\text { Sheet } \\
\text { Printing } \\
\text { Cost(I) }\end{array}$ \\
\hline Number of Different Types of Sheets & 100 & & \\
\hline SHEET \# & 1 & 150 & 0.03 \\
\hline Number of SKUs per Sheet(I) & 1 & & \\
\hline SKU AND \# OF UNITS PER SKU & 1 & 8 & \\
\hline SHEET \# & 2 & 150 & 0.03 \\
\hline Number of SKUs per Sheet(I) & 1 & & \\
\hline SKU AND \# OF UNITS PER SKU & 2 & 8 & \\
\hline SHEET \# & 3 & 150 & 0.03 \\
\hline Number of SKUs per Sheet(I) & 1 & & \\
\hline SKU AND \# OF UNITS PER SKU & 3 & 8 & \\
\hline SHEET \# & 4 & 150 & 0.03 \\
\hline Number of SKUs per Sheet(I) & 1 & & \\
\hline SKU AND \# OF UNITS PER SKU & 4 & 8 & \\
\hline SHEET \# & 5 & 150 & 0.03 \\
\hline Number of SKUs per Sheet(I) & 1 & & \\
\hline SKU AND \# OF UNITS PER SKU & 5 & 8 & \\
\hline SHEET \# & 6 & 150 & 0.03 \\
\hline Number of SKUs per Sheet(I) & 1 & & \\
\hline SKU AND \# OF UNITS PER SKU & 6 & 8 & \\
\hline SHEET \# & 7 & 150 & 0.03 \\
\hline Number of SKUs per Sheet(I) & 1 & & \\
\hline SKU AND \# OF UNITS PER SKU & 7 & 8 & \\
\hline SHEET \# & 8 & 150 & 0.03 \\
\hline Number of SKUs per Sheet(I) & 1 & & \\
\hline SKU AND \# OF UNITS PER SKU & 8 & 8 & \\
\hline SHEET \# & 9 & 150 & 0.03 \\
\hline Number of SKUs per Sheet(I) & 1 & & \\
\hline SKU AND \# OF UNITS PER SKU & 9 & 8 & \\
\hline SHEET \# & 10 & 150 & 0.03 \\
\hline Number of SKUs per Sheet(I) & 1 & & \\
\hline SKU AND \# OF UNITS PER SKU & 10 & 8 & \\
\hline
\end{tabular}




\begin{tabular}{|l|r|r|r|}
\hline SHEET \# & $\mathbf{1 1}$ & $\mathbf{1 5 0}$ & $\mathbf{0 . 0 3}$ \\
\hline Number of SKUs per Sheet(I) & 1 & & \\
\hline SKU AND \# OF UNITS PER SKU & 11 & 8 & \\
\hline SHEET \# & $\mathbf{1 2}$ & $\mathbf{1 5 0}$ & $\mathbf{0 . 0 3}$ \\
\hline Number of SKUs per Sheet(I) & 1 & & \\
\hline SKU AND \# OF UNITS PER SKU & 12 & 8 & \\
\hline SHEET \# & $\mathbf{1 3}$ & $\mathbf{1 5 0}$ & $\mathbf{0 . 0 3}$ \\
\hline Number of SKUs per Sheet(I) & 1 & & \\
\hline SKU AND \# OF UNITS PER SKU & 13 & 8 & \\
\hline SHEET \# & $\mathbf{1 4}$ & $\mathbf{1 5 0}$ & $\mathbf{0 . 0 3}$ \\
\hline Number of SKUs per Sheet(I) & 1 & & \\
\hline SKU AND \# OF UNITS PER SKU & 14 & 8 & \\
\hline SHEET \# & $\mathbf{1 5}$ & $\mathbf{1 5 0}$ & $\mathbf{0 . 0 3}$ \\
\hline Number of SKUs per Sheet(I) & 1 & & \\
\hline SKU AND \# OF UNITS PER SKU & 15 & 8 & \\
\hline SHEET \# & $\mathbf{1 6}$ & $\mathbf{1 5 0}$ & $\mathbf{0 . 0 3}$ \\
\hline Number of SKUs per Sheet(I) & 1 & & \\
\hline SKU AND \# OF UNITS PER SKU & 16 & 8 & \\
\hline SHEET \# & $\mathbf{1 7}$ & $\mathbf{1 5 0}$ & $\mathbf{0 . 0 3}$ \\
\hline Number of SKUs per Sheet(I) & 1 & & \\
\hline SKU AND \# OF UNITS PER SKU & 17 & 8 & \\
\hline SHEET \# & $\mathbf{1 8}$ & $\mathbf{1 5 0}$ & $\mathbf{0 . 0 3}$ \\
\hline Number of SKUs per Sheet(I) & 1 & & \\
\hline SKU AND \# OF UNITS PER SKU & 18 & 8 & \\
\hline SHEET \# & $\mathbf{1 9}$ & $\mathbf{1 5 0}$ & $\mathbf{0 . 0 3}$ \\
\hline Number of SKUs per Sheet(I) & 1 & & \\
\hline SKU AND \# OF UNITS PER SKU & 19 & 8 & \\
\hline SHEET \# & $\mathbf{2 0}$ & $\mathbf{1 5 0}$ & $\mathbf{0 . 0 3}$ \\
\hline Number of SKUs per Sheet(I) & 1 & & \\
\hline SKU AND \# OF UNITS PER SKU & 20 & 8 & \\
\hline SHEET \# & $\mathbf{2 1}$ & $\mathbf{1 5 0}$ & $\mathbf{0 . 0 3}$ \\
\hline Number of SKUs per Sheet(I) & 1 & & \\
\hline SKU AND \# OF UNITS PER SKU & 21 & 8 & \\
\hline SHEET \# & $\mathbf{2 2}$ & $\mathbf{1 5 0}$ & $\mathbf{0 . 0 3}$ \\
\hline Number of SKUs per Sheet(I) & 1 & & \\
\hline SKU AND \# OF UNITS PER SKU & 22 & 8 & \\
\hline SHEET \# & $\mathbf{2 3}$ & $\mathbf{1 5 0}$ & $\mathbf{0 . 0 3}$ \\
\hline Number of SKUs per Sheet(I) & 1 & & \\
\hline SKU AND \# OF UNITS PER SKU & $\mathbf{2 3}$ & 8 & $\mathbf{0 . 0 3}$ \\
\hline SHEET \# & & & \\
\hline Number of SKUs per Sheet(I) & & & \\
\hline SKU AND \# OF UNITS PER SKU & & & \\
\hline
\end{tabular}




\begin{tabular}{|l|r|r|r|} 
SHEET \# & $\mathbf{2 5}$ & $\mathbf{1 5 0}$ & $\mathbf{0 . 0 3}$ \\
\hline Number of SKUs per Sheet(I) & 1 & & \\
\hline SKU AND \# OF UNITS PER SKU & 25 & 8 & \\
\hline SHEET \# & $\mathbf{2 6}$ & $\mathbf{1 5 0}$ & $\mathbf{0 . 0 3}$ \\
\hline Number of SKUs per Sheet(I) & 1 & & \\
\hline SKU AND \# OF UNITS PER SKU & 26 & 8 & \\
\hline SHEET \# & $\mathbf{2 7}$ & $\mathbf{1 5 0}$ & $\mathbf{0 . 0 3}$ \\
\hline Number of SKUs per Sheet(I) & 1 & & \\
\hline SKU AND \# OF UNITS PER SKU & 27 & 8 & \\
\hline SHEET \# & $\mathbf{2 8}$ & $\mathbf{1 5 0}$ & $\mathbf{0 . 0 3}$ \\
\hline Number of SKUS per Sheet(I) & 1 & & \\
\hline SKU AND \# OF UNITS PER SKU & 28 & 8 & \\
\hline SHEET \# & $\mathbf{2 9}$ & $\mathbf{1 5 0}$ & $\mathbf{0 . 0 3}$ \\
\hline Number of SKUs per Sheet(I) & 1 & & \\
\hline SKU AND \# OF UNITS PER SKU & 29 & 8 & \\
\hline SHEET \# & $\mathbf{3 0}$ & $\mathbf{1 5 0}$ & $\mathbf{0 . 0 3}$ \\
\hline Number of SKUS per Sheet(I) & 1 & & \\
\hline SKU AND \# OF UNITS PER SKU & 30 & 8 & \\
\hline SHEET \# & $\mathbf{3 1}$ & $\mathbf{1 5 0}$ & $\mathbf{0 . 0 3}$ \\
\hline Number of SKUs per Sheet(I) & 1 & & \\
\hline SKU AND \# OF UNITS PER SKU & 31 & 8 & \\
\hline SHEET \# & $\mathbf{3 2}$ & $\mathbf{1 5 0}$ & $\mathbf{0 . 0 3}$ \\
\hline Number of SKUs per Sheet(I) & 1 & & \\
\hline SKU AND \# OF UNITS PER SKU & 32 & 8 & \\
\hline SHEET \# & $\mathbf{3 3}$ & $\mathbf{1 5 0}$ & $\mathbf{0 . 0 3}$ \\
\hline Number of SKUs per Sheet(I) & 1 & & \\
\hline SKU AND \# OF UNITS PER SKU & 33 & 8 & \\
\hline SHEET \# & $\mathbf{3 4}$ & $\mathbf{1 5 0}$ & $\mathbf{0 . 0 3}$ \\
\hline Number of SKUs per Sheet(I) & 1 & & \\
\hline SKU AND \# OF UNITS PER SKU & 34 & 8 & \\
\hline SHEET \# & $\mathbf{3 5}$ & $\mathbf{1 5 0}$ & $\mathbf{0 . 0 3}$ \\
\hline Number of SKUs per Sheet(I) & 1 & & \\
\hline SKU AND \# OF UNITS PER SKU & 35 & 8 & \\
\hline SHEET \# & $\mathbf{3 6}$ & $\mathbf{1 5 0}$ & $\mathbf{0 . 0 3}$ \\
\hline Number of SKUs per Sheet(I) & 1 & & \\
\hline SKU AND \# OF UNITS PER SKU & 36 & 8 & \\
\hline SHEET \# & $\mathbf{3 7}$ & $\mathbf{1 5 0}$ & $\mathbf{0 . 0 3}$ \\
\hline Number of SKUs per Sheet(I) & 1 & & \\
\hline SKU AND \# OF UNITS PER SKU & & & \\
\hline SHEET \# & $\mathbf{0 . 0 3}$ \\
\hline Number of SKUs per Sheet(I) & & & \\
\hline SKU AND \# OF UNITS PER SKU & & & \\
\hline
\end{tabular}




\begin{tabular}{|c|c|c|c|}
\hline SHEET \# & 39 & 150 & 0.03 \\
\hline Number of SKUs per Sheet(I) & 1 & & \\
\hline SKU AND \# OF UNITS PER SKU & 39 & 8 & \\
\hline SHEET \# & 40 & 150 & 0.03 \\
\hline Number of SKUs per Sheet(I) & 1 & & \\
\hline SKU AND \# OF UNITS PER SKU & 40 & 8 & \\
\hline SHEET \# & 41 & 150 & 0.03 \\
\hline Number of SKUs per Sheet(I) & 1 & & \\
\hline SKU AND \# OF UNITS PER SKU & 41 & 8 & \\
\hline SHEET \# & 42 & 150 & 0.03 \\
\hline Number of SKUs per Sheet(I) & 1 & & \\
\hline SKU AND \# OF UNITS PER SKU & 42 & 8 & \\
\hline SHEET \# & 43 & 150 & 0.03 \\
\hline Number of SKUs per Sheet(I) & 1 & & \\
\hline SKU AND \# OF UNITS PER SKU & 43 & 8 & \\
\hline SHEET \# & 44 & 150 & 0.03 \\
\hline Number of SKUs per Sheet(I) & 1 & & \\
\hline SKU AND \# OF UNITS PER SKU & 44 & 8 & \\
\hline SHEET \# & 45 & 150 & 0.03 \\
\hline Number of SKUs per Sheet(I) & 1 & & \\
\hline SKU AND \# OF UNITS PER SKU & 45 & 8 & \\
\hline SHEET \# & 46 & 150 & 0.03 \\
\hline Number of SKUs per Sheet(I) & 1 & & \\
\hline SKU AND \# OF UNITS PER SKU & 46 & 8 & \\
\hline SHEET \# & 47 & 150 & 0.03 \\
\hline Number of SKUs per Sheet(I) & 1 & & \\
\hline SKU AND \# OF UNITS PER SKU & 47 & 8 & \\
\hline SHEET \# & 48 & 150 & 0.03 \\
\hline Number of SKUs per Sheet(I) & 1 & & \\
\hline SKU AND \# OF UNITS PER SKU & 48 & 8 & \\
\hline SHEET \# & 49 & 150 & 0.03 \\
\hline Number of SKUs per Sheet(I) & 1 & & \\
\hline SKU AND \# OF UNITS PER SKU & 49 & 8 & \\
\hline SHEET \# & 50 & 150 & 0.03 \\
\hline Number of SKUs per Sheet(I) & 1 & & \\
\hline SKU AND \# OF UNITS PER SKU & 50 & 8 & \\
\hline SHEET \# & 51 & 150 & 0.03 \\
\hline Number of SKUs per Sheet(I) & 3 & & \\
\hline SKU AND \# OF UNITS PER SKU & 1 & 2 & \\
\hline SKU AND \# OF UNITS PER SKU & 2 & 3 & \\
\hline SKU AND \# OF UNITS PER SKU & 3 & 3 & \\
\hline SHEET \# & 52 & 150 & 0.03 \\
\hline
\end{tabular}




\begin{tabular}{|c|c|c|c|}
\hline Number of SKUs per Sheet(I) & 5 & & \\
\hline SKU AND \# OF UNITS PER SKU & 2 & 1 & \\
\hline SKU AND \# OF UNITS PER SKU & 3 & 1 & \\
\hline SKU AND \# OF UNITS PER SKU & 4 & 2 & \\
\hline SKU AND \# OF UNITS PER SKU & 5 & 2 & \\
\hline SKU AND \# OF UNITS PER SKU & 6 & 2 & \\
\hline SHEET \# & 53 & 150 & 0.03 \\
\hline Number of SKUs per Sheet(I) & 3 & & \\
\hline SKU AND \# OF UNITS PER SKU & 1 & 3 & \\
\hline SKU AND \# OF UNITS PER SKU & 6 & 2 & \\
\hline SKU AND \# OF UNITS PER SKU & 7 & 3 & \\
\hline SHEET \# & 54 & 150 & 0.03 \\
\hline Number of SKUs per Sheet(I) & 4 & & \\
\hline SKU AND \# OF UNITS PER SKU & 8 & 2 & \\
\hline SKU AND \# OF UNITS PER SKU & 9 & 2 & \\
\hline SKU AND \# OF UNITS PER SKU & 10 & 2 & \\
\hline SKU AND \# OF UNITS PER SKU & 11 & 2 & \\
\hline SHEET \# & 55 & 150 & 0.03 \\
\hline Number of SKUs per Sheet(I) & 3 & & \\
\hline SKU AND \# OF UNITS PER SKU & 31 & 2 & \\
\hline SKU AND \# OF UNITS PER SKU & 9 & 3 & \\
\hline SKU AND \# OF UNITS PER SKU & 14 & 3 & \\
\hline SHEET \# & 56 & 150 & 0.03 \\
\hline Number of SKUs per Sheet(I) & 4 & & \\
\hline SKU AND \# OF UNITS PER SKU & 13 & 2 & \\
\hline SKU AND \# OF UNITS PER SKU & 14 & 2 & \\
\hline SKU AND \# OF UNITS PER SKU & 15 & 3 & \\
\hline SKU AND \# OF UNITS PER SKU & 16 & 1 & \\
\hline SHEET \# & 57 & 150 & 0.03 \\
\hline Number of SKUs per Sheet(I) & 2 & & \\
\hline SKU AND \# OF UNITS PER SKU & 17 & 3 & \\
\hline SKU AND \# OF UNITS PER SKU & 18 & 5 & \\
\hline SHEET \# & 58 & 150 & 0.03 \\
\hline Number of SKUs per Sheet(I) & 6 & & \\
\hline SKU AND \# OF UNITS PER SKU & 7 & 1 & \\
\hline SKU AND \# OF UNITS PER SKU & 16 & 1 & \\
\hline SKU AND \# OF UNITS PER SKU & 19 & 2 & \\
\hline SKU AND \# OF UNITS PER SKU & 20 & 2 & \\
\hline SKU AND \# OF UNITS PER SKU & 21 & 1 & \\
\hline SKU AND \# OF UNITS PER SKU & 22 & 1 & \\
\hline SHEET \# & 89 & 150 & 0.03 \\
\hline Number of SKUs per Sheet(I) & 3 & & \\
\hline SKU AND \# OF UNITS PER SKU & 23 & 2 & \\
\hline SKU AND \# OF UNITS PER SKU & 24 & 3 & \\
\hline SKU AND \# OF UNITS PER SKU & 25 & 3 & \\
\hline SHEET \# & 60 & 150 & 0.03 \\
\hline
\end{tabular}




\begin{tabular}{|c|c|c|c|}
\hline Number of SKUs per Sheet(I) & 4 & & \\
\hline SKU AND \# OF UNITS PER SKU & 18 & 2 & \\
\hline SKU AND \# OF UNITS PER SKU & 21 & 2 & \\
\hline SKU AND \# OF UNITS PER SKU & 26 & 2 & \\
\hline SKU AND \# OF UNITS PER SKU & 27 & 2 & \\
\hline SHEET \# & 61 & 150 & 0.03 \\
\hline Number of SKUs per Sheet(I) & 4 & & \\
\hline SKU AND \# OF UNITS PER SKU & 16 & 1 & \\
\hline SKU AND \# OF UNITS PER SKU & 22 & 1 & \\
\hline SKU AND \# OF UNITS PER SKU & 28 & 1 & \\
\hline SKU AND \# OF UNITS PER SKU & 29 & 5 & \\
\hline SHEET \# & 62 & 150 & 0.03 \\
\hline Number of SKUs per Sheet(I) & 5 & & \\
\hline SKU AND \# OF UNITS PER SKU & 30 & 1 & \\
\hline SKU AND \# OF UNITS PER SKU & 31 & 1 & \\
\hline SKU AND \# OF UNITS PER SKU & 32 & 2 & \\
\hline SKU AND \# OF UNITS PER SKU & 33 & 2 & \\
\hline SKU AND \# OF UNITS PER SKU & 34 & 1 & \\
\hline SHEET \# & 63 & 150 & 0.03 \\
\hline Number of SKUs per Sheet(I) & 3 & & \\
\hline SKU AND \# OF UNITS PER SKU & 28 & 3 & \\
\hline SKU AND \# OF UNITS PER SKU & 35 & 3 & \\
\hline SKU AND \# OF UNITS PER SKU & 39 & 2 & \\
\hline SHEET \# & 64 & 150 & 0.03 \\
\hline Number of SKUs per Sheet(I) & 2 & & \\
\hline SKU AND \# OF UNITS PER SKU & 36 & 4 & \\
\hline SKU AND \# OF UNITS PER SKU & 37 & 4 & \\
\hline SHEET \# & 65 & 150 & 0.03 \\
\hline Number of SKUs per Sheet(I) & 3 & & \\
\hline SKU AND \# OF UNITS PER SKU & 38 & 2 & \\
\hline SKU AND \# OF UNITS PER SKU & 40 & 5 & \\
\hline SKU AND \# OF UNITS PER SKU & 41 & 1 & \\
\hline SHEET \# & 66 & 150 & 0.03 \\
\hline Number of SKUs per Sheet(I) & 4 & & \\
\hline SKU AND \# OF UNITS PER SKU & 41 & 2 & \\
\hline SKU AND \# OF UNITS PER SKU & 42 & 2 & \\
\hline SKU AND \# OF UNITS PER SKU & 43 & 2 & \\
\hline SKU AND \# OF UNITS PER SKU & 44 & 2 & \\
\hline SHEET \# & 67 & 150 & 0.03 \\
\hline Number of SKUs per Sheet(I) & 3 & & \\
\hline SKU AND \# OF UNITS PER SKU & 42 & 1 & \\
\hline SKU AND \# OF UNITS PER SKU & 45 & 3 & \\
\hline SKU AND \# OF UNITS PER SKU & 46 & 4 & \\
\hline SHEET \# & 68 & 150 & 0.03 \\
\hline
\end{tabular}




\begin{tabular}{|c|c|c|c|}
\hline Number of SKUs per Sheet(I) & 4 & & \\
\hline SKU AND \# OF UNITS PER SKU & 47 & 2 & \\
\hline SKU AND \# OF UNITS PER SKU & 48 & 2 & \\
\hline SKU AND \# OF UNITS PER SKU & 49 & 2 & \\
\hline SKU AND \# OF UNITS PER SKU & 50 & 2 & \\
\hline SHEET \# & 69 & 150 & 0.03 \\
\hline Number of SKUs per Sheet(I) & 3 & & \\
\hline SKU AND \# OF UNITS PER SKU & 46 & 2 & \\
\hline SKU AND \# OF UNITS PER SKU & 36 & 4 & \\
\hline SKU AND \# OF UNITS PER SKU & 23 & 2 & \\
\hline SHEET \# & 70 & 150 & 0.03 \\
\hline Number of SKUs per Sheet(I) & 4 & & \\
\hline SKU AND \# OF UNITS PER SKU & 20 & 2 & \\
\hline SKU AND \# OF UNITS PER SKU & 19 & 2 & \\
\hline SKU AND \# OF UNITS PER SKU & 16 & 1 & \\
\hline SKU AND \# OF UNITS PER SKU & 15 & 3 & \\
\hline SHEET \# & 71 & 150 & 0.03 \\
\hline Number of SKUs per Sheet(I) & 8 & & \\
\hline SKU AND \# OF UNITS PER SKU & 45 & 1 & \\
\hline SKU AND \# OF UNITS PER SKU & 14 & 1 & \\
\hline SKU AND \# OF UNITS PER SKU & 48 & 1 & \\
\hline SKU AND \# OF UNITS PER SKU & 47 & 1 & \\
\hline SKU AND \# OF UNITS PER SKU & 46 & 1 & \\
\hline SKU AND \# OF UNITS PER SKU & 45 & 1 & \\
\hline SKU AND \# OF UNITS PER SKU & 44 & 1 & \\
\hline SKU AND \# OF UNITS PER SKU & 43 & 1 & \\
\hline SHEET \# & 72 & 150 & 0.03 \\
\hline Number of SKUs per Sheet(I) & 8 & & \\
\hline SKU AND \# OF UNITS PER SKU & 32 & 1 & \\
\hline SKU AND \# OF UNITS PER SKU & 34 & 1 & \\
\hline SKU AND \# OF UNITS PER SKU & 35 & 1 & \\
\hline SKU AND \# OF UNITS PER SKU & 25 & 1 & \\
\hline SKU AND \# OF UNITS PER SKU & 36 & 1 & \\
\hline SKU AND \# OF UNITS PER SKU & 40 & 1 & \\
\hline SKU AND \# OF UNITS PER SKU & 41 & 1 & \\
\hline SKU AND \# OF UNITS PER SKU & 42 & 1 & \\
\hline SHEET \# & 73 & 150 & 0.03 \\
\hline Number of SKUs per Sheet(I) & 8 & & \\
\hline SKU AND \# OF UNITS PER SKU & 31 & 1 & \\
\hline SKU AND \# OF UNITS PER SKU & 30 & 1 & \\
\hline SKU AND \# OF UNITS PER SKU & 29 & 1 & \\
\hline SKU AND \# OF UNITS PER SKU & 3 & 1 & \\
\hline SKU AND \# OF UNITS PER SKU & 6 & 1 & \\
\hline SKU AND \# OF UNITS PER SKU & 9 & 1 & \\
\hline SKU AND \# OF UNITS PER SKU & 28 & 1 & \\
\hline SKU AND \# OF UNITS PER SKU & 15 & 1 & \\
\hline SHEET \# & 74 & 150 & 0.03 \\
\hline
\end{tabular}




\begin{tabular}{|c|c|c|c|}
\hline Number of SKUs per Sheet(I) & 3 & & \\
\hline SKU AND \# OF UNITS PER SKU & 13 & 3 & \\
\hline SKU AND \# OF UNITS PER SKU & 30 & 3 & \\
\hline SKU AND \# OF UNITS PER SKU & 40 & 2 & \\
\hline SHEET \# & 75 & 150 & 0.03 \\
\hline Number of SKUs per Sheet(I) & 2 & & \\
\hline SKU AND \# OF UNITS PER SKU & 17 & 4 & \\
\hline SKU AND \# OF UNITS PER SKU & 25 & 4 & \\
\hline SHEET \# & 76 & 150 & 0.03 \\
\hline Number of SKUs per Sheet(I) & 2 & & \\
\hline SKU AND \# OF UNITS PER SKU & 27 & 4 & \\
\hline SKU AND \# OF UNITS PER SKU & 46 & 4 & \\
\hline SHEET \# & 77 & 150 & 0.03 \\
\hline Number of SKUs per Sheet(I) & 2 & & \\
\hline SKU AND \# OF UNITS PER SKU & 20 & 4 & \\
\hline SKU AND \# OF UNITS PER SKU & 26 & 4 & \\
\hline SHEET \# & 78 & 150 & 0.03 \\
\hline Number of SKUs per Sheet(I) & 4 & & \\
\hline SKU AND \# OF UNITS PER SKU & 10 & 3 & \\
\hline SKU AND \# OF UNITS PER SKU & 74 & 2 & \\
\hline SKU AND \# OF UNITS PER SKU & 36 & 2 & \\
\hline SKU AND \# OF UNITS PER SKU & 19 & 1 & \\
\hline SHEET \# & 79 & 150 & 0.03 \\
\hline Number of SKUs per Sheet $(I)$ & 4 & & \\
\hline SKU AND \# OF UNITS PER SKU & 50 & 2 & \\
\hline SKU AND \# OF UNITS PER SKU & 40 & 2 & \\
\hline SKU AND \# OF UNITS PER SKU & 33 & 2 & \\
\hline SKU AND \# OF UNITS PER SKU & 53 & 2 & \\
\hline SHEET \# & & 150 & 0.03 \\
\hline \multicolumn{4}{|l|}{ Number of SKUs per Sheet(I) } \\
\hline SKU AND \# OF UNITS PER SKU & 13 & 2 & \\
\hline SKU AND \# OF UNITS PER SKU & 25 & 2 & \\
\hline SKU AND \# OF UNITS PER SKU & 35 & 1 & \\
\hline SKU AND \# OF UNITS PER SKU & 38 & 2 & \\
\hline SKU AND \# OF UNITS PER SKU & 44 & 1 & \\
\hline SHEET \# & 81 & 150 & 0.03 \\
\hline Number of SKUs per Sheet(I) & 5 & & \\
\hline SKU AND \# OF UNITS PER SKU & 33 & 2 & \\
\hline SKU AND \# OF UNITS PER SKU & 22 & 1 & \\
\hline SKU AND \# OF UNITS PER SKU & 32 & 1 & \\
\hline SKU AND \# OF UNITS PER SKU & 23 & 1 & \\
\hline SKU AND \# OF UNITS PER SKU & 21 & 3 & \\
\hline SHEET \# & 82 & 150 & 0.03 \\
\hline Number of SKUs per Sheet(I) & 5 & & \\
\hline SKU AND \# OF UNITS PER SKU & 14 & 1 & \\
\hline SKU AND \# OF UNITS PER SKU & 17 & 1 & \\
\hline
\end{tabular}




\begin{tabular}{|c|c|c|c|}
\hline SKU AND \# OF UNITS PER SKU & 34 & 2 & \\
\hline SKU AND \# OF UNITS PER SKU & 32 & 2 & \\
\hline SKU AND \# OF UNITS PER SKU & 35 & 2 & \\
\hline SHEET \# & 83 & 150 & 0.03 \\
\hline Number of SKUs per Sheet(I) & 5 & & \\
\hline SKU AND \# OF UNITS PER SKU & 15 & 1 & \\
\hline SKU AND \# OF UNITS PER SKU & 25 & 2 & \\
\hline SKU AND \# OF UNITS PER SKU & 35 & 2 & \\
\hline SKU AND \# OF UNITS PER SKU & 45 & 1 & \\
\hline SKU AND \# OF UNITS PER SKU & 49 & 2 & \\
\hline SHEET \# & 84 & 150 & 0.03 \\
\hline Number of SKUs per Sheet(I) & 5 & & \\
\hline SKU AND \# OF UNITS PER SKU & 7 & 3 & \\
\hline SKU AND \# OF UNITS PER SKU & 17 & 2 & \\
\hline SKU AND \# OF UNITS PER SKU & 27 & 1 & \\
\hline SKU AND \# OF UNITS PER SKU & 71 & 1 & \\
\hline SKU AND \# OF UNITS PER SKU & 45 & 1 & \\
\hline SHEET \# & 85 & 150 & 0.03 \\
\hline Number of SKUs per Sheet(I) & 4 & & \\
\hline SKU AND \# OF UNITS PER SKU & 8 & 3 & \\
\hline SKU AND \# OF UNITS PER SKU & 18 & 1 & \\
\hline SKU AND \# OF UNITS PER SKU & 28 & 2 & \\
\hline SKU AND \# OF UNITS PER SKU & 24 & 2 & \\
\hline SHEET \# & 86 & 150 & 0.03 \\
\hline Number of SKUs per Sheet(I) & 4 & & \\
\hline SKU AND \# OF UNITS PER SKU & 1 & 2 & \\
\hline SKU AND \# OF UNITS PER SKU & 36 & 2 & \\
\hline SKU AND \# OF UNITS PER SKU & 21 & 2 & \\
\hline SKU AND \# OF UNITS PER SKU & 24 & 2 & \\
\hline SHEET \# & 87 & 150 & 0.03 \\
\hline Number of SKUs per Sheet(I) & 4 & & \\
\hline SKU AND \# OF UNITS PER SKU & 22 & 2 & \\
\hline SKU AND \# OF UNITS PER SKU & 35 & 2 & \\
\hline SKU AND \# OF UNITS PER SKU & 43 & 2 & \\
\hline SKU AND \# OF UNITS PER SKU & 44 & 2 & \\
\hline SHEET \# & 88 & 150 & 0.03 \\
\hline Number of SKUs per Sheet(I) & 4 & & \\
\hline SKU AND \# OF UNITS PER SKU & 3 & 2 & \\
\hline SKU AND \# OF UNITS PER SKU & 12 & 3 & \\
\hline SKU AND \# OF UNITS PER SKU & 9 & 3 & \\
\hline SKU AND \# OF UNITS PER SKU & 6 & 1 & \\
\hline SHEET \# & 89 & 150 & 0.03 \\
\hline Number of SKUs per Sheet(I) & 2 & & \\
\hline SKU AND \# OF UNITS PER SKU & 23 & 5 & \\
\hline SKU AND \# OF UNITS PER SKU & 38 & 3 & \\
\hline SHEET \# & 90 & 150 & 0.03 \\
\hline
\end{tabular}




\begin{tabular}{|c|c|c|c|}
\hline Number of SKUs per Sheet(I) & 3 & & \\
\hline SKU AND \# OF UNITS PER SKU & 22 & 3 & \\
\hline SKU AND \# OF UNITS PER SKU & 28 & 2 & \\
\hline SKU AND \# OF UNITS PER SKU & 8 & 3 & \\
\hline SHEET \# & 91 & 150 & 0.03 \\
\hline Number of SKUs per Sheet(I) & 3 & & \\
\hline SKU AND \# OF UNITS PER SKU & 36 & 2 & \\
\hline SKU AND \# OF UNITS PER SKU & 7 & 2 & \\
\hline SKU AND \# OF UNITS PER SKU & 43 & 4 & \\
\hline SHEET \# & 92 & 150 & 0.03 \\
\hline Number of SKUs per Sheet(I) & 3 & & \\
\hline SKU AND \# OF UNITS PER SKU & 6 & 2 & \\
\hline SKU AND \# OF UNITS PER SKU & 38 & 2 & \\
\hline SKU AND \# OF UNITS PER SKU & 7 & 4 & \\
\hline SHEET \# & 93 & 150 & 0.03 \\
\hline Number of SKUs per Sheet(I) & 3 & & \\
\hline SKU AND \# OF UNITS PER SKU & 12 & 3 & \\
\hline SKU AND \# OF UNITS PER SKU & 5 & 3 & \\
\hline SKU AND \# OF UNITS PER SKU & 3 & 2 & \\
\hline SHEET \# & 94 & 150 & 0.03 \\
\hline Number of SKUs per Sheet(I) & 3 & & \\
\hline SKU AND \# OF UNITS PER SKU & 4 & 3 & \\
\hline SKU AND \# OF UNITS PER SKU & 25 & 2 & \\
\hline SKU AND \# OF UNITS PER SKU & 50 & 3 & \\
\hline SHEET \# & 95 & 150 & 0.03 \\
\hline Number of SKUs per Sheet(I) & 3 & & \\
\hline SKU AND \# OF UNITS PER SKU & 2 & 2 & \\
\hline SKU AND \# OF UNITS PER SKU & 40 & 3 & \\
\hline SKU AND \# OF UNITS PER SKU & 26 & 3 & \\
\hline SHEET \# & 96 & 150 & 0.03 \\
\hline Number of SKUs per Sheet(I) & 4 & & \\
\hline SKU AND \# OF UNITS PER SKU & 10 & 2 & \\
\hline SKU AND \# OF UNITS PER SKU & 4 & 2 & \\
\hline SKU AND \# OF UNITS PER SKU & 39 & 2 & \\
\hline SKU AND \# OF UNITS PER SKU & 49 & 2 & \\
\hline SHEET \# & 97 & 150 & 0.03 \\
\hline Number of SKUs per Sheet(I) & 4 & & \\
\hline SKU AND \# OF UNITS PER SKU & 8 & 2 & \\
\hline SKU AND \# OF UNITS PER SKU & 11 & 2 & \\
\hline SKU AND \# OF UNITS PER SKU & 21 & 2 & \\
\hline SKU AND \# OF UNITS PER SKU & 47 & 2 & \\
\hline SHEET \# & 98 & 150 & 0.03 \\
\hline Number of SKUs per Sheet(I) & 4 & & \\
\hline SKU AND \# OF UNITS PER SKU & 1 & 2 & \\
\hline SKU AND \# OF UNITS PER SKU & 42 & 2 & \\
\hline
\end{tabular}




\begin{tabular}{|l|r|r|r|}
\hline SKU AND \# OF UNITS PER SKU & 46 & 2 & \\
\hline SKU AND \# OF UNITS PER SKU & 34 & 2 & \\
\hline SHEET \# & $\mathbf{9 9}$ & $\mathbf{1 5 0}$ & $\mathbf{0 . 0 3}$ \\
\hline Number of SKUs per Sheet(I) & 2 & & \\
\hline SKU AND \# OF UNITS PER SKU & 24 & 4 & \\
\hline SKU AND \# OF UNITS PER SKU & 44 & 4 & \\
\hline SHEET \# & 100 & $\mathbf{1 5 0}$ & $\mathbf{0 . 0 3}$ \\
\hline Number of SKUs per Sheet(I) & 2 & & \\
\hline SKU AND \# OF UNITS PER SKU & 31 & 4 & \\
\hline SKU AND \# OF UNITS PER SKU & 48 & 4 & \\
\hline
\end{tabular}


APPENDIX II: INVENTORY DATA FILE FOR SCENARIO 1 


\begin{tabular}{|c|c|c|c|c|}
\hline \multicolumn{5}{|c|}{ DEMAND DATA } \\
\hline SKU & $\begin{array}{c}\text { Total Monthly } \\
\text { Demand (Labels) }\end{array}$ & $\begin{array}{l}\text { Avg \# of Orders } \\
\text { per Month }\end{array}$ & $\begin{array}{c}\text { Mean Order } \\
\text { Quantity (Labels) }\end{array}$ & $\begin{array}{l}\text { Interarrival } \\
\text { Time (Days) }\end{array}$ \\
\hline 1 & $\begin{array}{r}11,315 \\
\end{array}$ & 20 & 566 & 1.5 \\
\hline 2 & 10,455 & 15 & 697 & 2 \\
\hline 3 & 9,073 & 20 & 454 & 1.5 \\
\hline 4 & 9,512 & 10 & 952 & 3 \\
\hline 5 & 9,193 & 10 & 920 & 3 \\
\hline 6 & 7,642 & 20 & 383 & 1.5 \\
\hline 7 & 10,879 & 10 & 1,088 & 3 \\
\hline 8 & 9,712 & 20 & 486 & 1.5 \\
\hline 9 & 12,588 & 15 & 840 & 2 \\
\hline 10 & 8,904 & 5 & 1,781 & $\overline{6}$ \\
\hline 11 & 12,156 & 15 & 811 & 2 \\
\hline 12 & 9,859 & 20 & 493 & 1.5 \\
\hline 13 & 10,580 & 20 & 529 & 1.5 \\
\hline 14 & 9,804 & 10 & 981 & 3 \\
\hline 15 & 10,810 & 10 & 1,081 & 3 \\
\hline 16 & 11,153 & 20 & 558 & 1.5 \\
\hline 17 & 8,665 & 5 & 1,733 & 6 \\
\hline 18 & 10,115 & 30 & 338 & 1 \\
\hline 19 & 10,023 & 20 & 502 & 1.5 \\
\hline 20 & 8,883 & 20 & 445 & 1.5 \\
\hline 21 & 9,547 & 5 & 1,910 & 6 \\
\hline 22 & 10,171 & 20 & 509 & 1.5 \\
\hline 23 & 10,393 & 20 & 520 & 1.5 \\
\hline 24 & 10,931 & 20 & 547 & 1.5 \\
\hline 25 & 12,629 & 15 & 842 & 2 \\
\hline 26 & 13,145 & 15 & 877 & $\overline{2}$ \\
\hline 27 & 10,638 & 15 & 710 & 2 \\
\hline 28 & 12,037 & 20 & 602 & 1.5 \\
\hline 29 & 9,844 & 5 & 1,969 & 6 \\
\hline 30 & 12,718 & 20 & 636 & 1.5 \\
\hline 31 & 11,094 & 10 & 1,110 & 3 \\
\hline 32 & 8,822 & 10 & 883 & 3 \\
\hline 33 & 9,953 & 10 & 996 & 3 \\
\hline 34 & 9,741 & 10 & 975 & 3 \\
\hline 35 & 11,150 & 30 & 372 & 1 \\
\hline 36 & 9,933 & 20 & 497 & 1.5 \\
\hline 37 & 9,176 & 20 & 459 & 1.5 \\
\hline 38 & 8,885 & 10 & 889 & 3 \\
\hline 39 & 9,165 & 5 & 1,833 & 6 \\
\hline 40 & 7,736 & 10 & 774 & 3 \\
\hline 41 & 10,020 & 10 & 1,002 & 3 \\
\hline 42 & 12,191 & 20 & 610 & 1.5 \\
\hline 43 & 12,596 & 20 & 630 & 1.5 \\
\hline 44 & 10,643 & 20 & 533 & 1.5 \\
\hline 45 & 10,273 & 30 & 343 & 1 \\
\hline 46 & 8,875 & 20 & 444 & 1.5 \\
\hline 47 & 11,045 & 20 & 553 & 1.5 \\
\hline 48 & 10,733 & 20 & 537 & 1.5 \\
\hline 49 & 10,121 & 10 & 1,013 & 3 \\
\hline 50 & 10,260 & 20 & 513 & 1.5 \\
\hline
\end{tabular}


SCENARIO 1 EOQ DATA

\begin{tabular}{|c|c|c|c|c|c|c|c|c|c|}
\hline \multicolumn{7}{|c|}{ COSTS AND DEMANDS } & \multicolumn{3}{|c|}{ EOQ VALUES } \\
\hline SKU & $\begin{array}{c}\text { Mean } \\
\text { (Labels/Year) }\end{array}$ & $\begin{array}{c}\mathrm{SD} \\
\text { (Labels/Year) }\end{array}$ & $\begin{array}{c}\text { Fixed Cost } \\
\text { (\$/Setup) }\end{array}$ & $\begin{array}{l}\text { Holding Cost } \\
\text { (\$/Unit/Year) }\end{array}$ & $\begin{array}{l}\text { Setup lime } \\
\text { (Years) }\end{array}$ & $\begin{array}{c}\text { EOQProcessing } \\
\text { Time (Years) }\end{array}$ & $\begin{array}{c}\text { EOQ } \\
\text { (Labels) }\end{array}$ & $\begin{array}{c}\mathrm{R} \\
\text { (Labels) }\end{array}$ & $\begin{array}{l}\text { R+EOQ } \\
\text { (Labels) }\end{array}$ \\
\hline 1 & 132,162 & 6,990 & $\$ 150.00$ & $\$ 0.0221$ & 0.0004 & 0.0067 & 42,357 & 14,921 & 57,278 \\
\hline 2 & 133,447 & 4,082 & $\$ 150.00$ & $\$ 0.0221$ & 0.0004 & 0.0067 & 42,562 & 9,118 & 51,680 \\
\hline 3 & 134,493 & 1,732 & $\$ 150.00$ & $\$ 0.0221$ & 0.0004 & 0.0068 & 42,729 & 4,429 & 47,158 \\
\hline 4 & 122,763 & 1,551 & $\$ 150.00$ & $\$ 0.0221$ & 0.0004 & 0.0065 & 40,823 & 3,945 & 44,768 \\
\hline 5 & 118,578 & 2,088 & $\$ 150.00$ & $\$ 0.0221$ & 0.0004 & 0.0064 & 40,121 & 4,978 & 45,099 \\
\hline 6 & 133,694 & 1,775 & $\$ 150.00$ & $\$ 0.0221$ & 0.0004 & 0.0068 & 42,602 & 4,507 & 47,109 \\
\hline 7 & 121,899 & 3,381 & $\$ 150.00$ & $\$ 0.0221$ & 0.0004 & 0.0064 & 40,679 & 7,596 & 48,275 \\
\hline 8 & 134,183 & 3,371 & $\$ 150.00$ & $\$ 0.0221$ & 0.0004 & 0.0068 & 42,679 & 7,704 & 50,383 \\
\hline 9 & 136,619 & 1,890 & $\$ 150.00$ & $\$ 0.0221$ & 0.0004 & 0.0068 & 43,065 & 4,768 & 47,833 \\
\hline 10 & 111,881 & 1,986 & $\$ 150.00$ & $\$ 0.0221$ & 0.0004 & 0.0062 & 38,972 & 4,709 & 43,681 \\
\hline 11 & 132,331 & 4,628 & $\$ 150.00$ & $\$ 0.0221$ & 0.0004 & 0.0067 & 42,384 & 10,199 & 52,583 \\
\hline 12 & 131,080 & 4,300 & $\$ 150.00$ & $\$ 0.0221$ & 0.0004 & 0.0067 & 42,183 & 9,528 & 51,711 \\
\hline 13 & 135,005 & 5,398 & $\$ 150.00$ & $\$ 0.0221$ & 0.0004 & 0.0068 & 42,810 & 11,767 & 54,577 \\
\hline 14 & 120,968 & 2,280 & $\$ 150.00$ & $\$ 0.0221$ & 0.0004 & 0.0064 & 40,523 & 5,385 & 45,908 \\
\hline 15 & 118,592 & 1,943 & $\$ 150.00$ & $\$ 0.0221$ & 0.0004 & 0.0064 & 40,123 & 4,687 & 44,810 \\
\hline 16 & 130,914 & 2,344 & $\$ 150.00$ & $\$ 0.0221$ & 0.0004 & 0.0067 & 42,156 & 5,615 & 47,771 \\
\hline 17 & 109,656 & 531 & $\$ 150.00$ & $\$ 0.0221$ & 0.0004 & 0.0061 & 38,582 & 1,777 & 40,359 \\
\hline 18 & 125,791 & 968 & $\$ 150.00$ & $\$ 0.0221$ & 0.0004 & 0.0066 & 41,323 & 2,810 & 44,133 \\
\hline 19 & 135,649 & 3,334 & $\$ 150.00$ & $\$ 0.0221$ & 0.0004 & 0.0068 & 42,912 & 7,646 & 50,558 \\
\hline 20 & 128,068 & 4,878 & $\$ 150.00$ & $\$ 0.0221$ & 0.0004 & 0.0066 & 41,696 & 10,654 & 52,350 \\
\hline 21 & 111,093 & 2,169 & $\$ 150.00$ & $\$ 0.0221$ & 0.0004 & 0.0062 & 38,834 & 5,066 & 43,900 \\
\hline 22 & 127,856 & 3,635 & $\$ 150.00$ & $\$ 0.0221$ & 0.0004 & 0.0066 & 41,661 & 8,165 & 49,826 \\
\hline 23 & 131,156 & 4,924 & $\$ 150.00$ & $\$ 0.0221$ & 0.0004 & 0.0067 & 42,195 & 10,778 & 52,973 \\
\hline 24 & 131,897 & 2,834 & $\$ 150.00$ & $\$ 0.0221$ & 0.0004 & 0.0067 & 42,314 & 6,606 & 48,920 \\
\hline 25 & 135,556 & 4,056 & $\$ 150.00$ & $\$ 0.0221$ & 0.0004 & 0.0068 & 42,897 & 9,088 & 51,985 \\
\hline 26 & 137,689 & 4,175 & $\$ 150.00$ & $\$ 0.0221$ & 0.0004 & 0.0069 & 43,233 & 9,348 & 52,581 \\
\hline 27 & 134,256 & 1,194 & $\$ 150.00$ & $\$ 0.0221$ & 0.0004 & 0.0068 & 42,691 & 3,350 & 46,041 \\
\hline 28 & 131,244 & 2,652 & $\$ 150.00$ & $\$ 0.0221$ & 0.0004 & 0.0067 & 42,209 & 6,234 & 48,443 \\
\hline 29 & 111,508 & 1,440 & $\$ 150.00$ & $\$ 0.0221$ & 0.0004 & 0.0062 & 38,907 & 3,613 & 42,520 \\
\hline 30 & 132,280 & 7,582 & $\$ 150.00$ & $\$ 0.0221$ & 0.0004 & 0.0067 & 42,376 & 16,105 & 58,481 \\
\hline 31 & 122,959 & 4,767 & $\$ 150.00$ & $\$ 0.0221$ & 0.0004 & 0.0065 & 40,855 & 10,379 & 51,234 \\
\hline 32 & 119,140 & 2,095 & $\$ 150.00$ & $\$ 0.0221$ & 0.0004 & 0.0064 & 40,216 & 4,998 & 45,214 \\
\hline 33 & 121,998 & 2,977 & $\$ 150.00$ & $\$ 0.0221$ & 0.0004 & 0.0065 & 40,695 & 6,789 & 47,484 \\
\hline 34 & 120,450 & 1,864 & $\$ 150.00$ & $\$ 0.0221$ & 0.0004 & 0.0064 & 40,437 & 4,549 & 44,986 \\
\hline 35 & 125,375 & 3,985 & $\$ 150.00$ & $\$ 0.0221$ & 0.0004 & 0.0065 & 41,255 & 8,840 & 50,095 \\
\hline 36 & 131,964 & 4,154 & $\$ 150.00$ & $\$ 0.0221$ & 0.0004 & 0.0067 & 42,325 & 9,246 & 51,571 \\
\hline 37 & 131,082 & 4,242 & $\$ 150.00$ & $\$ 0.0221$ & 0.0004 & 0.0067 & 42,183 & 9,413 & 51,596 \\
\hline 38 & 121,156 & 2,654 & $\$ 150.00$ & $\$ 0.0221$ & 0.0004 & 0.0064 & 40,555 & 6,135 & 46,690 \\
\hline 39 & 111,643 & 913 & $\$ 150.00$ & $\$ 0.0221$ & 0.0004 & 0.0062 & 38,930 & 2,561 & 41,491 \\
\hline 40 & 120,396 & 3,669 & $\$ 150.00$ & $\$ 0.0221$ & 0.0004 & 0.0064 & 40,427 & 8,157 & 48,584 \\
\hline 41 & 119,458 & 4,636 & $\$ 150.00$ & $\$ 0.0221$ & 0.0004 & 0.0064 & 40,270 & 10,083 & 50,353 \\
\hline 42 & 128,750 & 2,626 & $\$ 150.00$ & $\$ 0.0221$ & 0.0004 & 0.0066 & 41,806 & 6,157 & 47,963 \\
\hline 43 & 130,840 & 2,350 & $\$ 150.00$ & $\$ 0.0221$ & 0.0004 & 0.0067 & 42,144 & 5,627 & 47,771 \\
\hline 44 & 133,890 & 3,405 & $\$ 150.00$ & $\$ 0.0221$ & 0.0004 & 0.0068 & 42,633 & 7,768 & 50,401 \\
\hline 45 & 125,230 & 4,217 & $\$ 150.00$ & $\$ 0.0221$ & 0.0004 & 0.0065 & 41,231 & 9,302 & 50,533 \\
\hline 46 & 134,490 & 8,828 & $\$ 150.00$ & $\$ 0.0221$ & 0.0004 & 0.0068 & 42,728 & 18,620 & 61,348 \\
\hline 47 & 132,766 & 2,717 & $\$ 150.00$ & $\$ 0.0221$ & 0.0004 & 0.0067 & 42,453 & 6,381 & 48,834 \\
\hline 48 & 133,001 & 3,880 & $\$ 150.00$ & $\$ 0.0221$ & 0.0004 & 0.0067 & 42,491 & 8,710 & 51,201 \\
\hline 49 & 118,779 & 1,754 & $\$ 150.00$ & $\$ 0.0221$ & 0.0004 & 0.0064 & 40,155 & 4,312 & 44,467 \\
\hline 50 & 129,841 & 1,239 & $\$ 150.00$ & $\$ 0.0221$ & 0.0004 & 0.0067 & 41,983 & 3,394 & 45,377 \\
\hline
\end{tabular}

Total Yearly Demand

6,345,510 Labels 
SCENARIO 1 INVENTORY DATA

\begin{tabular}{|c|c|c|c|c|c|}
\hline SKU & $\begin{array}{c}\text { Initial Inventory } \\
\text { (Labels) }\end{array}$ & $\begin{array}{c}\text { Big S } \\
\text { (Labels) }\end{array}$ & $\begin{array}{l}\text { Little s } \\
\text { (Labels) }\end{array}$ & $\begin{array}{l}\text { Unit Holding Cost } \\
\text { (\$/Unit/Year) }\end{array}$ & $\begin{array}{l}\text { Waiting to Print } \\
\text { (Labels) }\end{array}$ \\
\hline \# of SKUs & 50 & & & & \\
\hline 1 & 57,278 & 57,278 & 14,921 & $\$ 0.0221$ & 0 \\
\hline 2 & 51,680 & 51,680 & 9,118 & $\$ 0.0221$ & 0 \\
\hline 3 & 47,158 & 47,158 & 4,429 & $\$ 0.0221$ & $\overline{0}$ \\
\hline 4 & 44,768 & 44,768 & 3,945 & $\$ 0.0221$ & $\overline{0}$ \\
\hline 5 & 45,099 & 45,099 & 4,978 & $\$ 0.0221$ & 0 \\
\hline$\overline{6}$ & 47,109 & 47,109 & 4,507 & $\$ 0.0221$ & 0 \\
\hline 7 & 48,275 & 48,275 & 7,596 & $\$ 0.0221$ & 0 \\
\hline 8 & 50,383 & 50,383 & 7,704 & $\$ 0.0221$ & 0 \\
\hline$\overline{9}$ & 47,833 & 47,833 & 4,768 & $\$ 0.0221$ & 0 \\
\hline 10 & 43,681 & 43,681 & 4,709 & $\$ 0.0221$ & 0 \\
\hline 11 & 52,583 & 52,583 & 10,199 & $\$ 0.0221$ & 0 \\
\hline 12 & 51,711 & 51,711 & 9,528 & $\$ 0.0221$ & 0 \\
\hline 13 & 54,577 & 54,577 & 11,767 & $\$ 0.0221$ & 0 \\
\hline 14 & 45,908 & 45,908 & 5,385 & $\$ 0.0221$ & 0 \\
\hline 15 & 44,810 & 44,810 & 4,687 & $\$ 0.0221$ & 0 \\
\hline 16 & 47,771 & 47,771 & 5,615 & $\$ 0.0221$ & 0 \\
\hline 17 & 40,359 & 40,359 & 1,777 & $\$ 0.0221$ & 0 \\
\hline 18 & 44,133 & 44,133 & 2,810 & $\$ 0.0221$ & $\overline{0}$ \\
\hline 19 & 50,558 & 50,558 & 7,646 & $\$ 0.0221$ & $\overline{0}$ \\
\hline 20 & 52,350 & 52,350 & 10,654 & $\$ 0.0221$ & 0 \\
\hline 21 & 43,900 & 43,900 & 5,066 & $\$ 0.0221$ & 0 \\
\hline 22 & 49,826 & 49,826 & 8,165 & $\$ 0.0221$ & $\overline{0}$ \\
\hline 23 & 52,973 & 52,973 & 10,778 & $\$ 0.0221$ & $\overline{0}$ \\
\hline 24 & 48,920 & 48,920 & 6,606 & $\$ 0.0221$ & 0 \\
\hline 25 & 51,985 & 51,985 & 9,088 & $\$ 0.0221$ & 0 \\
\hline 26 & 52,581 & 52,581 & 9,348 & $\$ 0.0221$ & $\overline{0}$ \\
\hline 27 & 46,041 & 46,041 & 3,350 & $\$ 0.0221$ & 0 \\
\hline 28 & 48,443 & 48,443 & 6,234 & $\$ 0.0221$ & $\overline{0}$ \\
\hline 29 & 42,520 & 42,520 & 3,613 & $\$ 0.0221$ & $\overline{0}$ \\
\hline 30 & 58,481 & 58,481 & 16,105 & $\$ 0.0221$ & 0 \\
\hline 31 & 51,234 & 51,234 & 10,379 & $\$ 0.0221$ & $\overline{0}$ \\
\hline 32 & 45,214 & 45,214 & 4,998 & $\$ 0.0221$ & $\overline{0}$ \\
\hline 33 & 47,484 & 47,484 & 6,789 & $\$ 0.0221$ & $\overline{0}$ \\
\hline 34 & 44,986 & 44,986 & 4,549 & $\$ 0.0221$ & 0 \\
\hline 35 & 50,095 & 50,095 & 8,840 & $\$ 0.0221$ & $\overline{0}$ \\
\hline 36 & 51,571 & 51,571 & 9,246 & $\$ 0.0221$ & 0 \\
\hline 37 & 51,596 & 51,596 & 9,413 & $\$ 0.0221$ & $\overline{0}$ \\
\hline 38 & 46,690 & 46,690 & 6,135 & $\$ 0.0221$ & 0 \\
\hline 39 & 41,491 & 41,491 & 2,561 & $\$ 0.0221$ & 0 \\
\hline 40 & 48,584 & 48,584 & 8,157 & $\$ 0.0221$ & 0 \\
\hline 41 & 50,353 & 50,353 & 10,083 & $\$ 0.0221$ & $\overline{0}$ \\
\hline 42 & 47,963 & 47,963 & 6,157 & $\$ 0.0221$ & $\overline{0}$ \\
\hline 43 & 47,771 & 47,771 & 5,627 & $\$ 0.0221$ & $\overline{0}$ \\
\hline 44 & 50,401 & 50,401 & 7,768 & $\$ 0.0221$ & 0 \\
\hline 45 & 50,533 & 50,533 & 9,302 & $\$ 0.0221$ & 0 \\
\hline 46 & 61,348 & 61,348 & 18,620 & $\$ 0.0221$ & 0 \\
\hline 47 & 48,834 & 48,834 & $\begin{array}{r}6,381 \\
\end{array}$ & $\$ 0.0221$ & 0 \\
\hline 48 & 51,201 & 51,201 & 8,710 & $\$ 0.0221$ & $\overline{0}$ \\
\hline 49 & 44,467 & 44,467 & 4,312 & $\$ 0.0221$ & 0 \\
\hline 50 & 45,377 & 45,377 & 3,394 & $\$ 0.0221$ & $\overline{0}$ \\
\hline
\end{tabular}


APPENDIX III: INVENTORY DATA FILE FOR SCENARIO 2 


\begin{tabular}{|c|c|c|c|c|}
\hline \multicolumn{5}{|c|}{ DEMAND DATA } \\
\hline SKU & $\begin{array}{c}\text { Mean Monthly } \\
\text { Demand (Labels) } \\
\end{array}$ & \begin{tabular}{|c|} 
Avg \# of Orders per \\
Month
\end{tabular} & $\begin{array}{l}\text { Quantity } \\
\text { (Labels) } \\
\end{array}$ & $\begin{array}{c}\text { Mean Interarrival } \\
\text { Time (Days) } \\
\end{array}$ \\
\hline 1 & 27,704 & \begin{tabular}{|r|}
20 \\
\end{tabular} & 1,386 & $\begin{array}{r}1.5 \\
\end{array}$ \\
\hline 2 & 4,055 & 15 & 271 & 2 \\
\hline 3 & 6,009 & 20 & 301 & 1.5 \\
\hline 4 & 25,523 & 10 & 2,553 & 3 \\
\hline 5 & 4,064 & 10 & 407 & 3 \\
\hline 6 & 8,926 & 20 & 447 & 1.5 \\
\hline 7 & 4,707 & 10 & 471 & 3 \\
\hline 8 & 3,028 & 20 & 152 & 1.5 \\
\hline 9 & 2,517 & 15 & 168 & 2 \\
\hline 10 & 26,890 & 5 & 5,378 & 6 \\
\hline 11 & 4,905 & 15 & 327 & 2 \\
\hline 12 & 2,641 & 20 & 133 & 1.5 \\
\hline 13 & 3,042 & 20 & 153 & 1.5 \\
\hline 14 & 3,829 & 10 & 383 & 3 \\
\hline 15 & 4,209 & 10 & 421 & 3 \\
\hline 16 & 8,693 & 20 & 435 & 1.5 \\
\hline 17 & 3,185 & 5 & 637 & 6 \\
\hline 18 & 4,689 & 30 & 157 & 1 \\
\hline 19 & 3,371 & 20 & 169 & 1.5 \\
\hline 20 & 3,217 & 20 & 161 & 1.5 \\
\hline 21 & 22,984 & 5 & 4,597 & 6 \\
\hline 22 & 3,101 & 20 & 156 & 1.5 \\
\hline 23 & 9,799 & 20 & 490 & 1.5 \\
\hline 24 & 3,697 & 20 & 185 & 1.5 \\
\hline 25 & 39,530 & 15 & 2,636 & 2 \\
\hline 26 & 24,482 & 15 & 1,633 & 2 \\
\hline 27 & 4,304 & 15 & 287 & 2 \\
\hline 28 & 8,454 & 20 & 445 & 1.5 \\
\hline 29 & 3,576 & 5 & 716 & 6 \\
\hline 30 & 3,730 & 20 & 187 & 1.5 \\
\hline 31 & 24,193 & 10 & 2,420 & 3 \\
\hline 32 & 4,103 & 10 & 411 & 3 \\
\hline 33 & 3,885 & 10 & 389 & 3 \\
\hline 34 & 4,623 & 10 & 463 & 3 \\
\hline 35 & 38,680 & 30 & 1,290 & 1 \\
\hline 36 & 8,152 & 20 & 408 & 1.5 \\
\hline 37 & 29,068 & 20 & 1,454 & 1.5 \\
\hline 38 & 4,529 & 10 & 453 & 3 \\
\hline 39 & 3,928 & 5 & 786 & 6 \\
\hline 40 & 4,428 & 10 & 443 & 3 \\
\hline 41 & 4,757 & 10 & 476 & 3 \\
\hline 42 & 3,047 & 20 & 153 & 1.5 \\
\hline 43 & 9,040 & 20 & 452 & 1.5 \\
\hline 44 & 3,193 & 20 & 160 & 1.5 \\
\hline 45 & 5,115 & 30 & 171 & 1 \\
\hline 46 & 9,062 & 20 & 454 & 1.5 \\
\hline 47 & 31,080 & 20 & 1,554 & 1.5 \\
\hline 48 & 9,128 & 20 & 457 & 1.5 \\
\hline 49 & 4,608 & 10 & 461 & 3 \\
\hline 50 & 9,528 & 20 & 477 & 1.5 \\
\hline
\end{tabular}


SCENARIO 2 EOQ DATA

\begin{tabular}{|c|c|c|c|c|c|c|c|c|c|}
\hline \multicolumn{7}{|c|}{ COSTS AND DEMANDS } & \multicolumn{3}{|c|}{ EOQ VALUES } \\
\hline SKU & $\begin{array}{l}\text { Thean Demand } \\
\text { (Labels/Year) }\end{array}$ & $\begin{array}{c}\text { Standard Deviation } \\
\text { (Labels/Year) }\end{array}$ & $\begin{array}{l}\text { FIXed Cost } \\
\text { (\$/Setup) }\end{array}$ & $\begin{array}{l}\text { Holding Cost } \\
\text { (\$/Unit/Year) }\end{array}$ & $\begin{array}{l}\text { Setup IIme } \\
\text { (Years) }\end{array}$ & $\begin{array}{l}\text { EOQProcessing } \\
\text { Time (Years) }\end{array}$ & $\begin{array}{c}\text { EOQ } \\
\text { (Labels) }\end{array}$ & $\begin{array}{c}\mathrm{R} \\
\text { (Labels) }\end{array}$ & $\begin{array}{l}\text { R+EOQ } \\
\text { (Labels) }\end{array}$ \\
\hline 1 & 361,831 & 963 & $\$ 150.00$ & $\$ 0.0221$ & 0.0004 & 0.0111 & 70,084 & 6,091 & 76,175 \\
\hline 2 & 53,381 & 940 & $\$ 150.00$ & $\$ 0.0221$ & 0.0004 & 0.0043 & 26,919 & 2,129 & 29,048 \\
\hline 3 & 71,976 & 2,135 & $\$ 150.00$ & $\$ 0.0221$ & 0.0004 & 0.0050 & 31,258 & 4,655 & 35,913 \\
\hline 4 & 297,446 & 5,228 & $\$ 150.00$ & $\$ 0.0221$ & 0.0004 & 0.0101 & 63,544 & 13,571 & 77,115 \\
\hline 5 & 53,807 & 1,308 & $\$ 150.00$ & $\$ 0.0221$ & 0.0004 & 0.0043 & 27,027 & 2,868 & 29,895 \\
\hline 6 & 107,156 & 1,806 & $\$ 150.00$ & $\$ 0.0221$ & 0.0004 & 0.0060 & 38,140 & 4,302 & 42,442 \\
\hline 7 & 54,754 & 1,755 & $\$ 150.00$ & $\$ 0.0221$ & 0.0004 & 0.0043 & 27,263 & 3,769 & 31,032 \\
\hline 8 & 35,868 & 256 & $\$ 150.00$ & $\$ 0.0221$ & 0.0004 & 0.0035 & 22,066 & 652 & 22,718 \\
\hline 9 & 29,108 & 963 & $\$ 150.00$ & $\$ 0.0221$ & 0.0004 & 0.0032 & 19,878 & 2,029 & 21,907 \\
\hline 10 & 273,030 & 5,162 & $\$ 150.00$ & $\$ 0.0221$ & 0.0004 & 0.0097 & 60,880 & 13,069 & 73,949 \\
\hline 11 & 54,388 & 861 & $\$ 150.00$ & $\$ 0.0221$ & 0.0004 & 0.0043 & 27,172 & 1,979 & 29,151 \\
\hline 12 & 36,296 & 415 & $\$ 150.00$ & $\$ 0.0221$ & 0.0004 & 0.0035 & 22,198 & 972 & 23,170 \\
\hline 13 & 39,609 & 1,034 & $\$ 150.00$ & $\$ 0.0221$ & 0.0004 & 0.0037 & 23,188 & 2,229 & 25,417 \\
\hline 14 & 54,356 & 142 & $\$ 150.00$ & $\$ 0.0221$ & 0.0004 & 0.0043 & 27,164 & 539 & 27,703 \\
\hline 15 & 54,513 & 861 & $\$ 150.00$ & $\$ 0.0221$ & 0.0004 & 0.0043 & 27,203 & 1,980 & 29,183 \\
\hline 16 & 107,788 & 1,171 & $\$ 150.00$ & $\$ 0.0221$ & 0.0004 & 0.0061 & 38,252 & 3,038 & 41,290 \\
\hline 17 & 45,372 & 594 & $\$ 150.00$ & $\$ 0.0221$ & 0.0004 & 0.0039 & 24,818 & 1,385 & 26,203 \\
\hline 18 & 58,600 & 895 & $\$ 150.00$ & $\$ 0.0221$ & 0.0004 & 0.0045 & 28,205 & 2,076 & 30,281 \\
\hline 19 & 38,865 & 1,502 & $\$ 150.00$ & $\$ 0.0221$ & 0.0004 & 0.0036 & 22,970 & 3,161 & 26,131 \\
\hline 20 & 39,007 & 1,228 & $\$ 150.00$ & $\$ 0.0221$ & 0.0004 & 0.0036 & 23,012 & 2,615 & 25,627 \\
\hline 21 & 265,659 & 6,117 & $\$ 150.00$ & $\$ 0.0221$ & 0.0004 & 0.0095 & 60,052 & 14,869 & 74,921 \\
\hline 22 & 38,883 & 831 & $\$ 150.00$ & $\$ 0.0221$ & 0.0004 & 0.0036 & 22,975 & 1,819 & 24,794 \\
\hline 23 & 107,588 & 1,439 & $\$ 150.00$ & $\$ 0.0221$ & 0.0004 & 0.0061 & 38,217 & 3,573 & 41,790 \\
\hline 24 & 39,778 & 967 & $\$ 150.00$ & $\$ 0.0221$ & 0.0004 & 0.0037 & 23,238 & 2,097 & 25,335 \\
\hline 25 & 450,054 & 4,175 & $\$ 150.00$ & $\$ 0.0221$ & 0.0004 & 0.0124 & 78,163 & 14,108 & 92,271 \\
\hline 26 & 268,322 & 7,845 & $\$ 150.00$ & $\$ 0.0221$ & 0.0004 & 0.0096 & 60,353 & 18,366 & 78,719 \\
\hline 27 & 53,101 & 1,456 & $\$ 150.00$ & $\$ 0.0221$ & 0.0004 & 0.0043 & 26,849 & 3,160 & 30,009 \\
\hline 28 & 102,576 & 1,120 & $\$ 150.00$ & $\$ 0.0221$ & 0.0004 & 0.0059 & 37,316 & 2,888 & 40,204 \\
\hline 29 & 45,164 & 927 & $\$ 150.00$ & $\$ 0.0221$ & 0.0004 & 0.0039 & 24,761 & 2,049 & 26,810 \\
\hline 30 & 40,413 & 1,205 & $\$ 150.00$ & $\$ 0.0221$ & 0.0004 & 0.0037 & 23,423 & 2,576 & 25,999 \\
\hline 31 & 300,236 & 3,591 & $\$ 150.00$ & $\$ 0.0221$ & 0.0004 & 0.0101 & 63,841 & 10,341 & 74,182 \\
\hline 32 & 54,136 & 279 & $\$ 150.00$ & $\$ 0.0221$ & 0.0004 & 0.0043 & 27,109 & 813 & 27,922 \\
\hline 33 & 54,324 & 878 & $\$ 150.00$ & $\$ 0.0221$ & 0.0004 & 0.0043 & 27,156 & 2,012 & 29,168 \\
\hline 34 & 54,687 & 716 & $\$ 150.00$ & $\$ 0.0221$ & 0.0004 & 0.0043 & 27,247 & 1,690 & 28,937 \\
\hline 35 & 468,821 & 931 & $\$ 150.00$ & $\$ 0.0221$ & 0.0004 & 0.0126 & 79,776 & 7,979 & 87,755 \\
\hline 36 & 108,826 & 510 & $\$ 150.00$ & $\$ 0.0221$ & 0.0004 & 0.0061 & 38,436 & 1,726 & 40,162 \\
\hline 37 & 359,398 & 5,304 & $\$ 150.00$ & $\$ 0.0221$ & 0.0004 & 0.0111 & 69,848 & 14,731 & 84,579 \\
\hline 38 & 54,463 & 1,385 & $\$ 150.00$ & $\$ 0.0221$ & 0.0004 & 0.0043 & 27,191 & 3,026 & 30,217 \\
\hline 39 & 45,693 & 748 & $\$ 150.00$ & $\$ 0.0221$ & 0.0004 & 0.0039 & 24,906 & 1,696 & 26,602 \\
\hline 40 & 54,145 & 662 & $\$ 150.00$ & $\$ 0.0221$ & 0.0004 & 0.0043 & 27,111 & 1,578 & 28,689 \\
\hline 41 & 53,254 & 384 & $\$ 150.00$ & $\$ 0.0221$ & 0.0004 & 0.0043 & 26,887 & 1,015 & 27,902 \\
\hline 42 & 39,281 & 810 & $\$ 150.00$ & $\$ 0.0221$ & 0.0004 & 0.0037 & 23,092 & 1,779 & 24,871 \\
\hline 43 & 107,237 & 1,592 & $\$ 150.00$ & $\$ 0.0221$ & 0.0004 & 0.0060 & 38,154 & 3,876 & 42,030 \\
\hline 44 & 38,829 & 1,073 & $\$ 150.00$ & $\$ 0.0221$ & 0.0004 & 0.0036 & 22,959 & 2,303 & 25,262 \\
\hline 45 & 58,217 & 928 & $\$ 150.00$ & $\$ 0.0221$ & 0.0004 & 0.0045 & 28,112 & 2,139 & 30,251 \\
\hline 46 & 108,016 & 970 & $\$ 150.00$ & $\$ 0.0221$ & 0.0004 & 0.0061 & 38,292 & 2,639 & 40,931 \\
\hline 47 & 358,760 & 3,066 & $\$ 150.00$ & $\$ 0.0221$ & 0.0004 & 0.0111 & 69,786 & 10,245 & 80,031 \\
\hline 48 & 108,041 & 1,746 & $\$ 150.00$ & $\$ 0.0221$ & 0.0004 & 0.0061 & 38,297 & 4,192 & 42,489 \\
\hline 49 & 55,039 & 1,248 & $\$ 150.00$ & $\$ 0.0221$ & 0.0004 & 0.0043 & 27,334 & 2,757 & 30,091 \\
\hline 50 & 107,716 & 1,603 & $\$ 150.00$ & $\$ 0.0221$ & 0.0004 & 0.0061 & 38,239 & 3,902 & 42,141 \\
\hline
\end{tabular}


SCENARIO 2 INVENTORY DATA

\begin{tabular}{|c|c|c|c|c|c|}
\hline SKU & $\begin{array}{c}\text { Initial Inventory } \\
\text { (Labels) }\end{array}$ & $\begin{array}{c}\text { Big S } \\
\text { (Labels) }\end{array}$ & $\begin{array}{l}\text { Little s } \\
\text { (Labels) }\end{array}$ & $\begin{array}{l}\text { Unit Holding Cost } \\
\text { (\$/Unit/Year) }\end{array}$ & $\begin{array}{l}\text { Waiting to Print } \\
\text { (Labels) }\end{array}$ \\
\hline \# of SKUs & 50 & & & & \\
\hline 1 & 76,175 & 76,175 & 6,091 & $\$ 0.0221$ & 0 \\
\hline 2 & 29,048 & 29,048 & 2,129 & $\$ 0.0221$ & 0 \\
\hline 3 & 35,913 & 35,913 & 4,655 & $\$ 0.0221$ & 0 \\
\hline 4 & 77,115 & 77,115 & 13,571 & $\$ 0.0221$ & 0 \\
\hline 5 & 29,895 & 29,895 & 2,868 & $\$ 0.0221$ & 0 \\
\hline 6 & 42,442 & 42,442 & 4,302 & $\$ 0.0221$ & 0 \\
\hline 7 & 31,032 & 31,032 & 3,769 & $\$ 0.0221$ & 0 \\
\hline 8 & 22,718 & 22,718 & 652 & $\$ 0.0221$ & $\underline{0}$ \\
\hline 9 & 21,907 & 21,907 & 2,029 & $\$ 0.0221$ & 0 \\
\hline 10 & 73,949 & 73,949 & 13,069 & $\$ 0.0221$ & 0 \\
\hline 11 & 29,151 & 29,151 & 1,979 & $\$ 0.0221$ & 0 \\
\hline 12 & 23,170 & 23,170 & 972 & $\$ 0.0221$ & 0 \\
\hline 13 & 25,417 & 25,417 & 2,229 & $\$ 0.0221$ & 0 \\
\hline 14 & 27,703 & 27,703 & 539 & $\$ 0.0221$ & 0 \\
\hline 15 & 29,183 & 29,183 & 1,980 & $\$ 0.0221$ & 0 \\
\hline 16 & 41,290 & 41,290 & 3,038 & $\$ 0.0221$ & 0 \\
\hline 17 & 26,203 & 26,203 & 1,385 & $\$ 0.0221$ & $\underline{0}$ \\
\hline 18 & 30,281 & 30,281 & 2,076 & $\$ 0.0221$ & 0 \\
\hline 19 & 26,131 & 26,131 & 3,161 & $\$ 0.0221$ & 0 \\
\hline 20 & 25,627 & 25,627 & 2,615 & $\$ 0.0221$ & 0 \\
\hline 21 & 74,921 & 74,921 & 14,869 & $\$ 0.0221$ & 0 \\
\hline 22 & 24,794 & 24,794 & 1,819 & $\$ 0.0221$ & 0 \\
\hline 23 & 41,790 & 41,790 & 3,573 & $\$ 0.0221$ & 0 \\
\hline 24 & 25,335 & 25,335 & 2,097 & $\$ 0.0221$ & 0 \\
\hline 25 & 92,271 & 92,271 & 14,108 & $\$ 0.0221$ & 0 \\
\hline 26 & 78,719 & 78,719 & 18,366 & $\$ 0.0221$ & 0 \\
\hline 27 & 30,009 & 30,009 & 3,160 & $\$ 0.0221$ & 0 \\
\hline 28 & 40,204 & 40,204 & 2,888 & $\$ 0.0221$ & 0 \\
\hline 29 & 26,810 & 26,810 & 2,049 & $\$ 0.0221$ & 0 \\
\hline 30 & 25,999 & 25,999 & 2,576 & $\$ 0.0221$ & 0 \\
\hline 31 & 74,182 & 74,182 & 10,341 & $\$ 0.0221$ & 0 \\
\hline 32 & 27,922 & 27,922 & 813 & $\$ 0.0221$ & 0 \\
\hline 33 & 29,168 & 29,168 & 2,012 & $\$ 0.0221$ & 0 \\
\hline 34 & 28,937 & 28,937 & 1,690 & $\$ 0.0221$ & 0 \\
\hline 35 & 87,755 & 87,755 & 7,979 & $\$ 0.0221$ & 0 \\
\hline 36 & 40,162 & 40,162 & 1,726 & $\$ 0.0221$ & 0 \\
\hline 37 & 84,579 & 84,579 & 14,731 & $\$ 0.0221$ & 0 \\
\hline 38 & 30,217 & 30,217 & 3,026 & $\$ 0.0221$ & 0 \\
\hline 39 & 26,602 & 26,602 & 1,696 & $\$ 0.0221$ & 0 \\
\hline 40 & 28,689 & 28,689 & 1,578 & $\$ 0.0221$ & 0 \\
\hline 41 & 27,902 & 27,902 & 1,015 & $\$ 0.0221$ & $\overline{0}$ \\
\hline 42 & 24,871 & 24,871 & 1,779 & $\$ 0.0221$ & 0 \\
\hline 43 & 42,030 & 42,030 & 3,876 & $\$ 0.0221$ & 0 \\
\hline 44 & 25,262 & 25,262 & 2,303 & $\$ 0.0221$ & 0 \\
\hline 45 & 30,251 & 30,251 & 2,139 & $\$ 0.0221$ & $\overline{0}$ \\
\hline 46 & 40,931 & 40,931 & 2,639 & $\$ 0.0221$ & 0 \\
\hline 47 & 80,031 & 80,031 & 10,245 & $\$ 0.0221$ & 0 \\
\hline 48 & 42,489 & 42,489 & 4,192 & $\$ 0.0221$ & 0 \\
\hline 49 & 30,091 & 30,091 & 2,757 & $\$ 0.0221$ & 0 \\
\hline 50 & 42,141 & 42,141 & 3,902 & $\$ 0.0221$ & 0 \\
\hline
\end{tabular}


APPENDIX IV: INVENTORY DATA FOR SCENARIO 3 


\begin{tabular}{|c|c|c|c|c|}
\hline \multicolumn{5}{|c|}{ DEMAND DATA } \\
\hline SKU & \begin{tabular}{|c|} 
Mean Monthly \\
Demand (Labels)
\end{tabular} & $\begin{array}{c}\text { Avg \# of Orders per } \\
\text { Month (Labels) }\end{array}$ & $\begin{array}{c}\text { Mean Order } \\
\text { Quantity (Labels) }\end{array}$ & $\begin{array}{l}\text { Interarrival } \\
\text { Time (Days) }\end{array}$ \\
\hline 1 & \begin{tabular}{|r|}
20,082 \\
\end{tabular} & 20 & $\begin{array}{r}1,005 \\
\end{array}$ & 1.5 \\
\hline 2 & 8,827 & 15 & 589 & 2 \\
\hline 3 & 9,954 & 20 & 498 & 1.5 \\
\hline 4 & 19,134 & 10 & 1,914 & 3 \\
\hline 5 & 7,823 & 10 & 783 & 3 \\
\hline 6 & 20,259 & 20 & 1,013 & 1.5 \\
\hline 7 & 7,821 & 10 & 783 & 3 \\
\hline 8 & 10,387 & 20 & 520 & 1.5 \\
\hline 9 & 8,867 & 15 & 592 & 2 \\
\hline 10 & 21,327 & 5 & 4,266 & $\overline{6}$ \\
\hline 11 & 8,937 & 15 & 596 & $\overline{2}$ \\
\hline 12 & 9,698 & 20 & 485 & 1.5 \\
\hline 13 & 10,170 & 20 & 509 & 1.5 \\
\hline 14 & 18,777 & 10 & 1,878 & 3 \\
\hline 15 & 8,078 & 10 & 808 & 3 \\
\hline 16 & 18,947 & 20 & 948 & 1.5 \\
\hline 17 & 8,681 & 5 & 1,737 & 6 \\
\hline 18 & 9,303 & 30 & 311 & 1 \\
\hline 19 & 19,229 & 20 & 962 & 1.5 \\
\hline 20 & 9,959 & 20 & 498 & 1.5 \\
\hline 21 & 21,488 & 5 & 4,298 & 6 \\
\hline 22 & 9,409 & 20 & 471 & 1.5 \\
\hline 23 & 23,662 & 20 & 1,184 & 1.5 \\
\hline 24 & 10,224 & 20 & 512 & 1.5 \\
\hline 25 & 21,498 & 15 & 1,434 & 2 \\
\hline 26 & 21,912 & 15 & 1,461 & 2 \\
\hline 27 & 8,554 & 15 & 571 & 2 \\
\hline 28 & 10,017 & 20 & 501 & 1.5 \\
\hline 29 & 8,855 & 5 & 1,771 & 6 \\
\hline 30 & 22,123 & 20 & 1,107 & 1.5 \\
\hline 31 & 21,123 & 10 & 2,113 & 3 \\
\hline 32 & 8,170 & 10 & 817 & 3 \\
\hline 33 & 18,862 & 10 & 1,887 & 3 \\
\hline 34 & 7,339 & 10 & 734 & 3 \\
\hline 35 & 8,843 & 30 & 295 & 1 \\
\hline 36 & 9,397 & 20 & 470 & 1.5 \\
\hline 37 & 18,813 & 20 & 941 & 1.5 \\
\hline 38 & 7,880 & 10 & 788 & 3 \\
\hline 39 & 8,618 & 5 & 1,724 & 6 \\
\hline 40 & 8,082 & 10 & 809 & 3 \\
\hline 41 & 21,222 & 10 & 2,123 & 3 \\
\hline 42 & 10,510 & 20 & 526 & 1.5 \\
\hline 43 & 10,674 & 20 & 534 & 1.5 \\
\hline 44 & 19,280 & 20 & 964 & 1.5 \\
\hline 45 & 8,737 & 30 & 292 & 1 \\
\hline 46 & 10,081 & 20 & 505 & 1.5 \\
\hline 47 & 19,320 & 20 & 966 & 1.5 \\
\hline 48 & 10,553 & 20 & 528 & 1.5 \\
\hline 49 & 20,295 & 10 & 2,030 & 3 \\
\hline 50 & 17,759 & 20 & 888 & 1.5 \\
\hline
\end{tabular}


SCENARIO 3 EQO DATA

\begin{tabular}{|c|c|c|c|c|c|c|c|c|c|}
\hline \multicolumn{7}{|c|}{ COSTS AND DEMANDS } & \multicolumn{3}{|c|}{ EOQ VALUES } \\
\hline SKU & $\begin{array}{l}\text { Mean Demand } \\
\text { (Labels/Year) }\end{array}$ & $\begin{array}{c}\text { StandardDeviation } \\
\text { (Labels/Year) }\end{array}$ & $\begin{array}{l}\text { Fixed Cost } \\
\text { (\$/Setup) }\end{array}$ & $\begin{array}{l}\text { Holding Cost } \\
\text { (\$/Unit/Year) }\end{array}$ & $\begin{array}{l}\text { Setup Iime } \\
\text { (Years) }\end{array}$ & $\begin{array}{c}\text { EOQProcessing } \\
\text { Time (Years) }\end{array}$ & $\begin{array}{c}\text { EOQ } \\
\text { (Labels) }\end{array}$ & $\begin{array}{c}\mathrm{R} \\
\text { (Labels) }\end{array}$ & $\begin{array}{l}\text { R+EOQ } \\
\text { (Labels) }\end{array}$ \\
\hline 1 & 227,999 & 2,301 & $\$ 150.00$ & \begin{tabular}{|}
0.0221 \\
\end{tabular} & 0.0004 & 0.0088 & 55,633 & 6,703 & 62,336 \\
\hline 2 & 108,402 & 1,147 & $\$ 150.00$ & $\$ 0.0221$ & 0.0004 & 0.0061 & 38,361 & 2,996 & 41,357 \\
\hline 3 & 119,241 & 1,845 & $\$ 150.00$ & $\$ 0.0221$ & 0.0004 & 0.0064 & 40,233 & 4,499 & 44,732 \\
\hline 4 & 240,832 & 4,470 & $\$ 150.00$ & $\$ 0.0221$ & 0.0004 & 0.0091 & 57,178 & 11,220 & 68,398 \\
\hline 5 & 96,306 & 1,780 & $\$ 150.00$ & $\$ 0.0221$ & 0.0004 & 0.0057 & 36,157 & 4,150 & 40,307 \\
\hline 6 & 226,459 & 463 & $\$ 150.00$ & $\$ 0.0221$ & 0.0004 & 0.0088 & 55,445 & 3,007 & 58,452 \\
\hline 7 & 96,629 & 579 & $\$ 150.00$ & $\$ 0.0221$ & 0.0004 & 0.0057 & 36,218 & 1,752 & 37,970 \\
\hline 8 & 121,902 & 1,121 & $\$ 150.00$ & $\$ 0.0221$ & 0.0004 & 0.0064 & 40,679 & 3,077 & 43,756 \\
\hline 9 & 107,979 & 1,018 & $\$ 150.00$ & $\$ 0.0221$ & 0.0004 & 0.0061 & 38,286 & 2,734 & 41,020 \\
\hline 10 & 240,596 & 2,131 & $\$ 150.00$ & $\$ 0.0221$ & 0.0004 & 0.0091 & 57,149 & 6,538 & 63,687 \\
\hline 11 & 107,744 & 1,160 & $\$ 150.00$ & $\$ 0.0221$ & 0.0004 & 0.0061 & 38,244 & 3,016 & 41,260 \\
\hline 12 & 121,025 & 2,140 & $\$ 150.00$ & $\$ 0.0221$ & 0.0004 & 0.0064 & 40,533 & 5,106 & 45,639 \\
\hline 13 & 119,195 & 766 & $\$ 150.00$ & $\$ 0.0221$ & 0.0004 & 0.0064 & 40,225 & 2,339 & 42,564 \\
\hline 14 & 239,375 & 2,597 & $\$ 150.00$ & $\$ 0.0221$ & 0.0004 & 0.0090 & 57,004 & 7,454 & 64,458 \\
\hline 15 & 95,574 & 1,402 & $\$ 150.00$ & $\$ 0.0221$ & 0.0004 & 0.0057 & 36,020 & 3,388 & 39,408 \\
\hline 16 & 227,681 & 300 & $\$ 150.00$ & $\$ 0.0221$ & 0.0004 & 0.0088 & 55,594 & 2,698 & 58,292 \\
\hline 17 & 104,694 & 669 & $\$ 150.00$ & $\$ 0.0221$ & 0.0004 & 0.0060 & 37,699 & 2,006 & 39,705 \\
\hline 18 & 108,597 & 1,150 & $\$ 150.00$ & $\$ 0.0221$ & 0.0004 & 0.0061 & 38,395 & 3,005 & 41,400 \\
\hline 19 & 228,388 & 2,322 & $\$ 150.00$ & $\$ 0.0221$ & 0.0004 & 0.0088 & 55,681 & 6,751 & 62,432 \\
\hline 20 & 121,631 & 1,888 & $\$ 150.00$ & $\$ 0.0221$ & 0.0004 & 0.0064 & 40,634 & 4,607 & 45,241 \\
\hline 21 & 238,455 & 2,646 & $\$ 150.00$ & $\$ 0.0221$ & 0.0004 & 0.0090 & 56,895 & 7,539 & 64,434 \\
\hline 22 & 121,164 & 1,690 & $\$ 150.00$ & $\$ 0.0221$ & 0.0004 & 0.0064 & 40,556 & 4,208 & 44,764 \\
\hline 23 & 276,042 & 4,309 & $\$ 150.00$ & $\$ 0.0221$ & 0.0004 & 0.0097 & 61,215 & 11,407 & 72,622 \\
\hline 24 & 1119,726 & 1,382 & $\$ 150.00$ & $\$ 0.0221$ & 0.0004 & 0.0064 & 40,315 & 3,578 & 43,893 \\
\hline 25 & 270,818 & 3,658 & $\$ 150.00$ & $\$ 0.0221$ & 0.0004 & 0.0096 & 60,633 & 10,027 & 70,660 \\
\hline 26 & 269,662 & 2,919 & $\$ 150.00$ & $\$ 0.0221$ & 0.0004 & 0.0096 & 60,503 & 8,533 & 69,036 \\
\hline 27 & 107,486 & 370 & $\$ 150.00$ & $\$ 0.0221$ & 0.0004 & 0.0061 & 38,198 & 1,434 & 39,632 \\
\hline 28 & 121,205 & 1,178 & $\$ 150.00$ & $\$ 0.0221$ & 0.0004 & 0.0064 & 40,563 & 3,184 & 43,747 \\
\hline 29 & 104,396 & 947 & $\$ 150.00$ & $\$ 0.0221$ & 0.0004 & 0.0060 & 37,645 & 2,559 & 40,204 \\
\hline 30 & 276,695 & 2,356 & $\$ 150.00$ & $\$ 0.0221$ & 0.0004 & 0.0097 & 61,287 & 7,512 & 68,799 \\
\hline 31 & 239,601 & 4,235 & $\$ 150.00$ & $\$ 0.0221$ & 0.0004 & 0.0090 & 57,031 & 10,733 & 67,764 \\
\hline 32 & 95,568 & 734 & $\$ 150.00$ & $\$ 0.0221$ & 0.0004 & 0.0057 & 36,019 & 2,052 & 38,071 \\
\hline 33 & 240,712 & 2,901 & $\$ 150.00$ & $\$ 0.0221$ & 0.0004 & 0.0091 & 57,163 & 8,080 & 65,243 \\
\hline 34 & 96,454 & 934 & $\$ 150.00$ & $\$ 0.0221$ & 0.0004 & 0.0057 & 36,185 & 2,461 & 38,646 \\
\hline 35 & 107,900 & 766 & $\$ 150.00$ & $\$ 0.0221$ & 0.0004 & 0.0061 & 38,272 & 2,230 & 40,502 \\
\hline 36 & 119,875 & 1,512 & $\$ 150.00$ & $\$ 0.0221$ & 0.0004 & 0.0064 & 40,340 & 3,839 & 44,179 \\
\hline 37 & 229,751 & 3,923 & \$ 150.00 & $\$ 0.0221$ & 0.0004 & 0.0089 & 55,847 & 9,971 & 65,818 \\
\hline 38 & 96,308 & 529 & $\$ 150.00$ & $\$ 0.0221$ & 0.0004 & 0.0057 & 36,158 & 1,649 & 37,807 \\
\hline 39 & 105,727 & 1,864 & $\$ 150.00$ & $\$ 0.0221$ & 0.0004 & 0.0060 & 37,885 & 4,405 & 42,290 \\
\hline 40 & 95,867 & 1,001 & $\$ 150.00$ & $\$ 0.0221$ & 0.0004 & 0.0057 & 36,075 & 2,589 & 38,664 \\
\hline 41 & 238,052 & 2,814 & $\$ 150.00$ & $\$ 0.0221$ & 0.0004 & 0.0090 & 56,847 & 7,868 & 64,715 \\
\hline 42 & 119,692 & 2,075 & $\$ 150.00$ & $\$ 0.0221$ & 0.0004 & 0.0064 & 40,309 & 4,963 & 45,272 \\
\hline 43 & 119,576 & 2,170 & $\$ 150.00$ & $\$ 0.0221$ & 0.0004 & 0.0064 & 40,290 & 5,151 & 45,441 \\
\hline 44 & 230,196 & 2,426 & $\$ 150.00$ & $\$ 0.0221$ & 0.0004 & 0.0089 & 55,901 & 6,984 & 62,885 \\
\hline 45 & 107,308 & 1,230 & $\$ 150.00$ & $\$ 0.0221$ & 0.0004 & 0.0061 & 38,167 & 3,153 & 41,320 \\
\hline 46 & 119,937 & 1,202 & $\$ 150.00$ & $\$ 0.0221$ & 0.0004 & 0.0064 & 40,350 & 3,219 & 43,569 \\
\hline 47 & 229,005 & 1,588 & $\$ 150.00$ & $\$ 0.0221$ & 0.0004 & 0.0088 & 55,756 & 5,292 & 61,048 \\
\hline 48 & 120,453 & 1,914 & $\$ 150.00$ & $\$ 0.0221$ & 0.0004 & 0.0064 & 40,437 & 4,648 & 45,085 \\
\hline 49 & 238,246 & 3,700 & $\$ 150.00$ & $\$ 0.0221$ & 0.0004 & 0.0090 & 56,870 & 9,643 & 66,513 \\
\hline 50 & 227,286 & 1,652 & $\$ 150.00$ & $\$ 0.0221$ & 0.0004 & 0.0088 & 55,546 & 5,396 & 60,942 \\
\hline
\end{tabular}

Total Yearly Demand

8,143,405 Labels 


\section{SCENARIO 3 INVENTORY DATA}

\begin{tabular}{|c|c|c|c|c|c|}
\hline SKU & $\begin{array}{l}\text { Initial Inventory } \\
\text { (Labels) }\end{array}$ & $\begin{array}{c}\text { Big S } \\
\text { (Labels) }\end{array}$ & $\begin{array}{l}\text { Little s } \\
\text { (Labels) }\end{array}$ & $\begin{array}{c}\text { Unit Holding Cost } \\
\text { (\$/Unit/Year) }\end{array}$ & $\begin{array}{l}\text { Waiting to Print } \\
\text { (Labels) }\end{array}$ \\
\hline \# of SKUs & 50 & & & & \\
\hline 1 & 62,336 & 62,336 & 6,703 & $\$ 0.0221$ & 0 \\
\hline 2 & 41,357 & 41,357 & 2,996 & $\$ 0.0221$ & 0 \\
\hline 3 & 44,732 & 44,732 & 4,499 & $\$ 0.0221$ & 0 \\
\hline 4 & 68,398 & 68,398 & 11,220 & $\$ 0.0221$ & 0 \\
\hline 5 & 40,307 & 40,307 & 4,150 & $\$ 0.0221$ & 0 \\
\hline 6 & 58,452 & 58,452 & 3,007 & $\$ 0.0221$ & 0 \\
\hline 7 & 37,970 & 37,970 & 1,752 & $\$ 0.0221$ & 0 \\
\hline 8 & 43,756 & 43,756 & 3,077 & $\$ 0.0221$ & $\overline{0}$ \\
\hline 9 & 41,020 & 41,020 & 2,734 & $\$ 0.0221$ & 0 \\
\hline 10 & 63,687 & 63,687 & 6,538 & $\$ 0.0221$ & 0 \\
\hline 11 & 41,260 & 41,260 & 3,016 & $\$ 0.0221$ & 0 \\
\hline 12 & 45,639 & 45,639 & 5,106 & $\$ 0.0221$ & 0 \\
\hline 13 & 42,564 & 42,564 & 2,339 & $\$ 0.0221$ & 0 \\
\hline 14 & 64,458 & 64,458 & 7,454 & $\$ 0.0221$ & 0 \\
\hline 15 & 39,408 & 39,408 & 3,388 & $\$ 0.0221$ & 0 \\
\hline 16 & 58,292 & 58,292 & 2,698 & $\$ 0.0221$ & 0 \\
\hline 17 & 39,705 & 39,705 & 2,006 & $\$ 0.0221$ & 0 \\
\hline 18 & 41,400 & 41,400 & 3,005 & $\$ 0.0221$ & 0 \\
\hline 19 & 62,432 & 62,432 & 6,751 & $\$ 0.0221$ & 0 \\
\hline 20 & 45,241 & 45,241 & 4,607 & $\$ 0.0221$ & 0 \\
\hline 21 & 64,434 & 64,434 & 7,539 & $\$ 0.0221$ & 0 \\
\hline 22 & 444,764 & 44,764 & 4,208 & $\$ 0.0221$ & 0 \\
\hline 23 & 72,622 & 72,622 & 11,407 & $\$ 0.0221$ & 0 \\
\hline 24 & 43,893 & 43,893 & 3,578 & $\$ 0.0221$ & 0 \\
\hline 25 & 70,660 & 70,660 & 10,027 & $\$ 0.0221$ & 0 \\
\hline 26 & 69,036 & 69,036 & 8,533 & $\$ 0.0221$ & 0 \\
\hline 27 & 39,632 & 39,632 & 1,434 & $\$ 0.0221$ & 0 \\
\hline 28 & 43,747 & 43,747 & 3,184 & $\$ 0.0221$ & 0 \\
\hline 29 & 40,204 & 40,204 & 2,559 & $\$ 0.0221$ & 0 \\
\hline 30 & 68,799 & 68,799 & 7,512 & $\$ 0.0221$ & 0 \\
\hline 31 & 67,764 & 67,764 & 10,733 & $\$ 0.0221$ & 0 \\
\hline 32 & 38,071 & 38,071 & 2,052 & $\$ 0.0221$ & 0 \\
\hline 33 & 65,243 & 65,243 & 8,080 & $\$ 0.0221$ & 0 \\
\hline 34 & 38,646 & 38,646 & 2,461 & $\$ 0.0221$ & 0 \\
\hline 35 & 40,502 & 40,502 & 2,230 & $\$ 0.0221$ & 0 \\
\hline 36 & 44,179 & 44,179 & 3,839 & $\$ 0.0221$ & 0 \\
\hline 37 & 65,818 & 65,818 & 9,971 & $\$ 0.0221$ & $\overline{0}$ \\
\hline 38 & 37,807 & 37,807 & 1,649 & $\$ 0.0221$ & 0 \\
\hline 39 & 42,290 & 42,290 & 4,405 & $\$ 0.0221$ & 0 \\
\hline 40 & 38,664 & 38,664 & 2,589 & $\$ 0.0221$ & 0 \\
\hline 41 & 64,715 & 64,715 & $7,8,868$ & $\$ 0.0221$ & 0 \\
\hline 42 & 45,272 & 45,272 & 4,963 & $\$ 0.0221$ & 0 \\
\hline 43 & 45,441 & 45,441 & 5,151 & $\$ 0.0221$ & $\overline{0}$ \\
\hline 44 & 62,885 & 62,885 & 6,984 & $\$ 0.0221$ & 0 \\
\hline 45 & 41,320 & 41,320 & 3,153 & $\$ 0.0221$ & 0 \\
\hline 46 & 43,569 & 43,569 & 3,219 & $\$ 0.0221$ & 0 \\
\hline 47 & 61,048 & 61,048 & 5,292 & $\$ 0.0221$ & 0 \\
\hline 48 & 45,085 & 45,085 & 4,648 & $\$ 0.0221$ & 0 \\
\hline 49 & 66,513 & 66,513 & 9,643 & $\$ 0.0221$ & 0 \\
\hline 50 & 60,942 & 60,942 & 5,396 & $\$ 0.0221$ & 0 \\
\hline
\end{tabular}


APPENDIX V: ORDER QUANTITY AND INTERARRIVAL TIME DISTRIBUTIONS

FOR SCENARIOS 1, 2, AND 3 
ORDER QUANTITY AND INTERARRIVAL TIME DISTRIBUTIONS

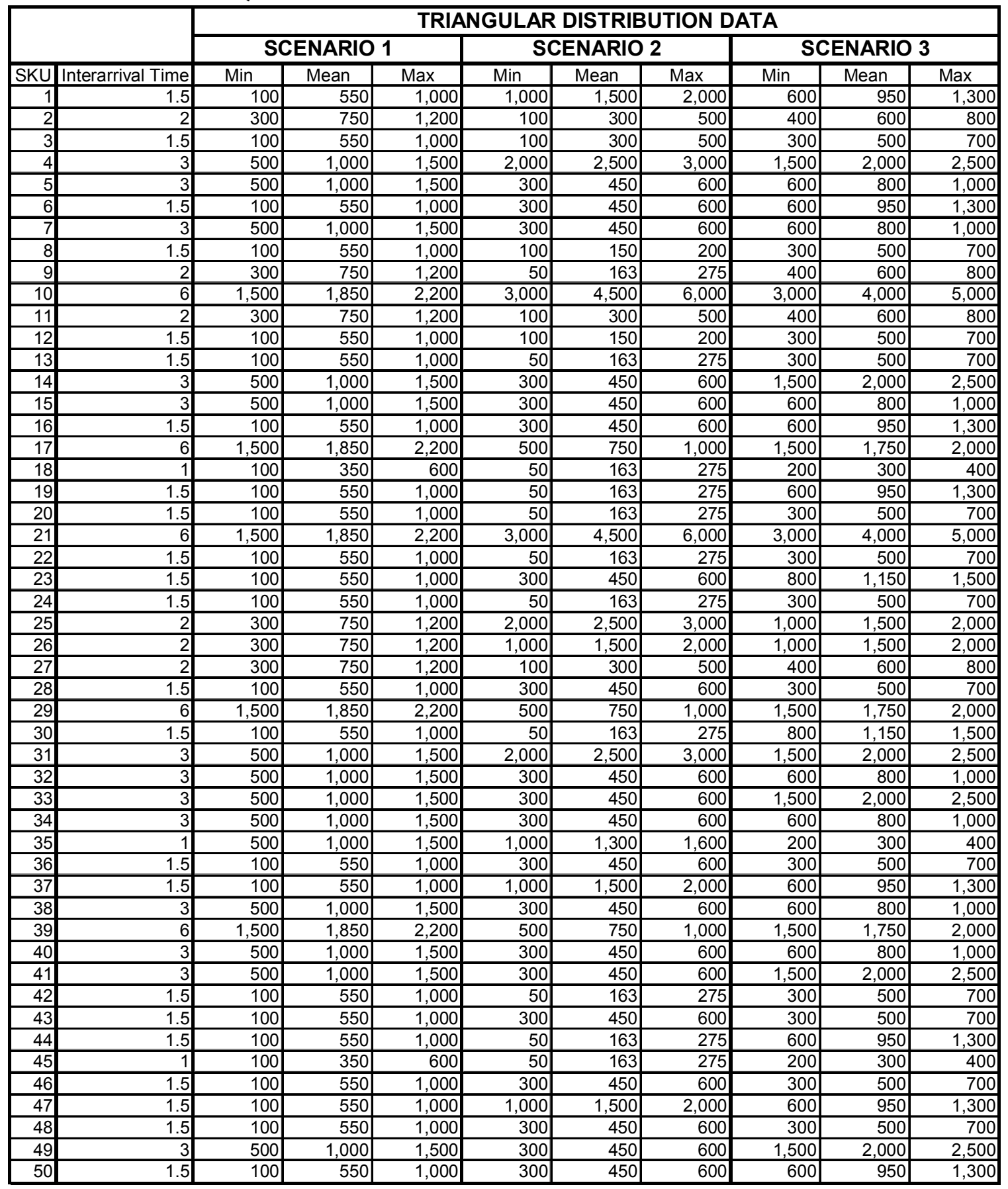


VITA

Dustin Allen Fackler was born on October 29, 1980 to Stephen and Marcia Fackler. Raised in Louisville, Kentucky, he attended grade school at Our Lady of Lourdes and Holy Trinity. He graduated high school in May 1999 from Trinity High School. He fulfilled his co-operative internships at United Parcel Service in the Aircraft Maintenance Industrial Engineering department and received his Bachelor of Science in Industrial Engineering in May 2006 from the University of Louisville J.B. Speed School of Engineering. Dustin is currently pursuing his Masters degree in Industrial Engineering at the University of Louisville. 